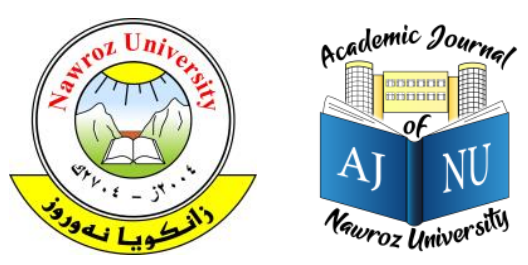

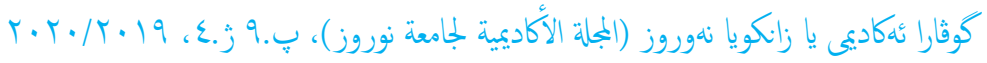

حقوق الطبع والنشر (2017. هذه مقالة الوصول اليها مفتوح موزعة تحت رخصة

e-ISSN: 2520-789X ،CC BY-NC-ND 4. 0. - المشاع الايداعي النسبي

https://doi.org/10.25007/ajnu.v9n4a941

\title{
دور التخطيط الاستراتيجي في استراتيجيات الاستدامة البيئية دراسة استطلاعية لآراء القيادات الادارية في عينة من شركات المياه المعدنية في محافظة دهوك
}

\author{
م. د. حكمت رشيد سلطان، كلية الادارة والاقتصاد، جامعة دهوك، كردستان العراق
}

تهدف الدراسة إلى النعرف على دور التخطيط الاستراتيجي من خلال مؤشراته المتثلة في (الرؤية والرسالة والاهداف الاستراتيجية والتهليل البيئي والصياغة الاستراتيجية والتقويم) في استراتيجيات

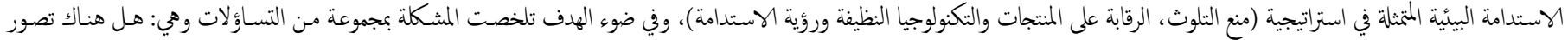

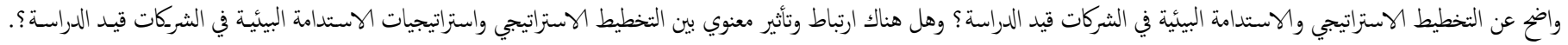

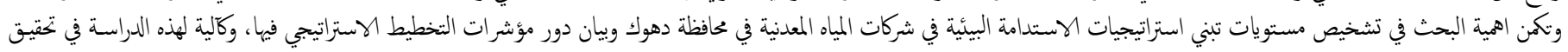

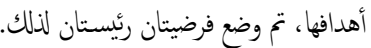

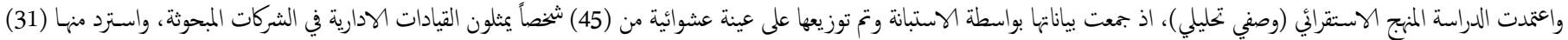

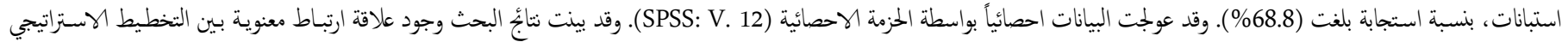

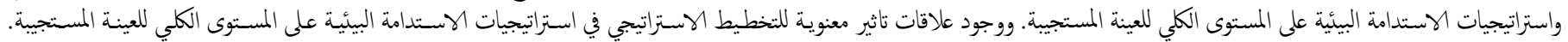

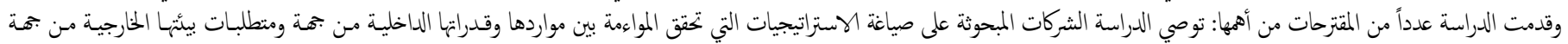

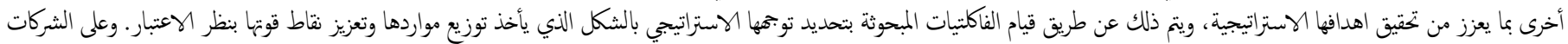

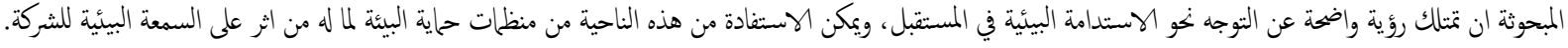

الكلمات الوفتاحية: التخطيط الاستراتيجي، الاستدامة البيئية، استراتيجيات الاستدامة البيئية، التكنولوجيا النظيفة، الرقابة على الانتاج.

1

التقليل من التكلفة و تخفيض معدلات الحوادث، و تطوير الأداء البيئي، كما آن احترام

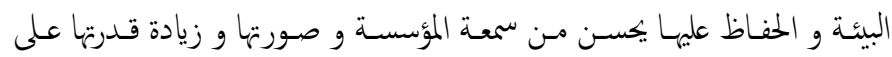
اكتساب أسواق جديدة و مستهلكين جدد.

مـن هنـا جـاءت الدراسـة للتعـرف عـلى دور التخطيط الاسـتراتيجي في استراتيجيات الاستدامة البيئية، وهذا مـا تم تناوله من خلال هذه الدراسة مـن مفاهيمها بطريقة نظرية ومن ثم تشخيص وتحليل علاقة الارتباط والاثر بين هذه المتغيرات بالشكل الذي ساعد على الوصول المى بموعة من الاستنتاجات والمقترحات.

1.1

ونتيجة للضغوطات المتزايدة من قبـل المعنيـن في مجال البيئة وخاصة من منظمات وتشمل 1.1.1 المفاهيم النظرية 1.1.1.1 التخطيط الاستراتيجي قدرتها التنافسية وتعظيم ربيتها، من خلال مـا تسهم به في القضاء على التلوث، و وتتضمن
يعـد التخطيط الاسـتراتيجي سمة مـن سهات العصر ـ الحـديث, وأداة رئيسة تمكن المنظلات من رسم المسارات الصحيحة لتقدم حركنا العلمية ضمن البيئة التي تعيش فيها وتتفاعل معها بغية تحقيق الاهداف المنشودة في البناء والتقدم. ويكن تطبيق مفهوم التخطيط الاستراتيجي في المنظلات لرفح جودة العملية التعليمة من خلال قيام تلك المنظات بتحديد الرؤية المستقبلة لها وتحديد غايتها على المدى الطويل، وتحديد أبعاد العلاقة المتوقعة بنها وبين بينتها بما يساعد في تحديد الفرص والمخاطر المحيطة، ونقاط الضعف والقوة المميزة لها وذلك بهدف اتخاذ القرارات الإستراتيجية على المدى البعيد

ومراجعتها وتقويمها. وجمعيات حاية البيئة تسعى الثركات المى تحقيق الكفاءة البيئية والفاعلية البيئية في ادائها. أن مراعاة الجوانب البيئة من طرف منظات الأعال تعد ركيزة أساسية لزيادة

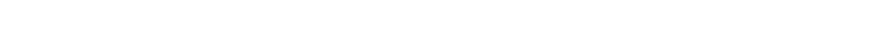




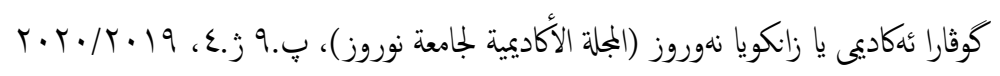

ان تحدث تأثيراً واضحاً في المستفيدين من خدماتها (عملاء او مساهمين) وفي مستويات التشغيل ومستويات الاداء للافراد والمديرين. الاستفادة القصوى من كافة الموارد البشرية والمادية والتنيـة والتنشغيلية التي

\section{ستساهم في تنفيذها.}

وحسب ما اشار اليه (البرادعي، 2005: 72) ان التخطيط الاستراتيجي هو الخطة التي توضح كيفية تحقيق الاهداف الاستراتيجية للمنظمة، وانها خريطة تفصيلية للاتجاه والاجراءات التي تنوي المنظمة اتباعها في تنفيذ انشطنها. وقد عرفه (Bryson) على

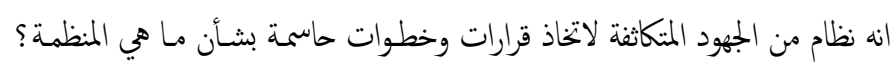
وماذا تعمل؟ وملماذا تعمل؟ (بو دولة، وصالحية، 2005: 92). وييين (السلطان، 2006: 8) ان التخطيط الاستراتيجي هو دراسة الواقع بكل أبعاده ومظاهره، من قوة وضعف وتحديات وفرص، ورسم رؤى وأهداف مستقبلة بناءً على ذلك، ثخ وضع برامج عملية تساعد على الانتقال إلى المستقبل المنشود. ويرى (المبارك، 2006: 7) ان التخطيط الاستراتيجي هو مجهود منظم على المدى الطويلل للمساعدة على اتخاذ القرار واقتراح الأنشطة وماهيتها وأسباب القيام بها مـن خلال التعمق في تحن تحليـل الوضع الحـالي والربط مـع المحيط وتحليـل التحـديات، ويتضمن التخطيط الاستراتيجي عملية تحديد الغايات والأهداف الاستراتيجية للمنظمة. ويبين (الهلالي، 2006: 2) ان التخطيط الاستراتيجي عبارة عن أنشطة تتعلق بتحديد عممة المنظمة وتحديد اهدافها الاستراتيجية وتصميم استراتيجيتها لتمكين المنظمة من العمل بكفاءة في البيئة الخارجيـة. ويرى البعض ان النخطيط الاسترانتجي يراد بـه تحويل التفكير الاستراتيجي إلى منهج قابل للتطبيق وبنفس الوقت موجه لتحقيق الغايات والاهداف والرسالة في نطاق السقف الزمني المحدد ضمن الخطة (الكبيسي-، 2006: 16). ويرى (بريدي، وآخرون، 2006: 360) ان التخطيط الاستراتيجي هو وسيلة لخلق معنى وفهم التوجه ومواصلته حينا تزداد صعوبة التكهن بالمستقبل باطراد، فهو عملية مستمرة تستطيع المنظمة من خلالها مواصلة الاتجاه من خلال ادخال تعديلات مع تخير البيئات الداخلية والخارجية.

في حين يشتق (Mintzberg) مفهوم التخطيط الاستراتيجي من ابعاد التخطيط الاربعة، وهذه الابعاد هي (الهلالي، 2006: 5): - - البعد الاول: التخطيط هو تفكير مستقبلي مرادف لاتخاذ القرارات.
1.1.1.1.1 مفهوم وتعريف التخطيط الاستراتيجي يعبر التخطيط الاستراتيجي عن دراسة الواقع بكل أبعاده ومظاهره، من قوة وضعف وتحديات وفرص، ويبنى تصورات وأهداف المستقبل بناءً على هذا الواقع ودراسات معمقة وشـاملة وبما يخقق الرسالة المتوخـاة، ثم يضع الخطط المسـتقبلية بعيداً عن الارتجاليـة أو السطحية، وبعيـداً عن تجاهـل التحـديات أو إهـال الفرص المواتيـة (Munitz, 1995:4) و. ويشير (القطامين، 2002: 94) إلى التخطيط الاستراتيجي بأنه الخطة الشاملة التي تحدد كيفية انجاز اهداف المنظمة ورساتها، وتسعى إلى تحقيق غاية ثنائية الأبعاد، فين جهة تقود إلى تعظيم الميزة التنافسية للمنظمة في نفس الوقت الذي تؤدي فيه إلى تقليل واحباط العبء التنافسيـ الذي يوابهـها. امـا (برايسون، 2003: 27) فـيرى ان التخطيط الاسـتراتيجي يعـــ بمثابـة بمحوعـة مـن المفـاهيم والإجراءات والأدوار المصمة لمساعدة القادة والمديرين على القيام بأعلالم، وهو المجهود المنظم لاتخاذ قرارات جوهرية والقيام بتصرفات اساسية من شأنها ان تشكل وتوجه منظمة ما او كيانا ما وان تحدد ما تغعله ولماذا تفعله. يعد التخطيط الاستراتيجي Strategic Planning أولى خطوات ومهام الإدارة الاستراتيجية، وهو يتعلق بتحديد اتجاه المنظمة في المستقبل الذي ينطوي بدوره على تحديد كل من رسالة المنظمة وأهدافها، بناء على تحليل الوضع الحالي والمستقبلي لكل من البيئة المحطة والقدرات الذاتية، بعدها يتم ترجمة تلك الأهداف إلى برامج وخطط على المستويات الاستراتيجية وقد ظهر التخطيط الاستراتيجي قبل ظهور مفهوم الإدارة الاستراتيجية، وساد حتى بداية السبعينيات في ظل افتراض مفاده سهولة التنبؤ بالمستقبل لأجل طويل، وكان المسؤولين عن التخطيط الاستراتيجي هم رجال الإدارة العليا الذين يكلفون باقي أعضاء المنظمة بعد ذلك بتنفيذ الخطط الاستراتيجية التي تم وضعها (توفيتق، 2004: 2). ويؤكد (السبتي، 2005: 2) ان أي خطة لا تكون استراتيجية الحا اذا توفر لها العديد من العوامل، وهذه العوامل هي: مدخلات ذات قيمة عالية تنري مضمون الاستراتيجية. الدع اللامحدود من الإدارة العليا للمنظمة.

ان يكون الدافع لها مواكبة التغييرات الخارجية والداخلية المجيطة ببيئة المنظمة. ان تخلق تصوراً واضحاً عا ستكون عليه المنظمة مستقبلاً. 


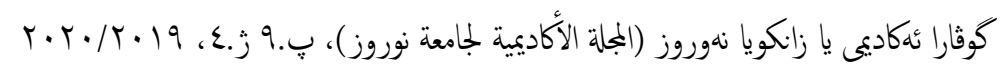

يسـاعد على إدراكـ وتقـدير ومعالجـة التهديـدات والفرص المتواجـدة في البيئة

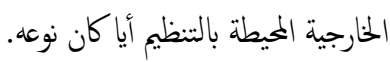

- - - - البعد الثاني: ان التخطيط يعبر عن محاولة واعية تستهدف ايجاد عملية متكاملة

لاتخاذ القرارات.

البعد الرابع: التخطيط هو برجة من خلال عملية تلي تحديد الاهداف (وتشمل 3.1.1.1.1 مؤشرات التخطيط الاستراتيجي. على الاجابة على اسئلة بـداياتها هي: كيف، متى، ايـن، ك). وهـذه الابعاد من خلال البحث في هذا المجال تبين ان الكتاب والباحثين منهم (برايسون، 2003) و (العارف، 2005) و (الكبيسي، 2006) و (بريدي، وآخرون، 2006) يتفقون على

\section{ان عناصر التخطيط الاستراتيجي تتمثل في الآتي:} - الرؤية الرسالة. الاهداف الاستراتيجية. SWOT تحليل

صياغة البدائل الاستراتيجية. التقويم والرقابة الاستراتيجية.

وعلى هـا الاسـاس فان دراستنا سيتعتمد على هـذه المؤشرات لقيـاس التخطيط الاستراتيجي للمنظات عينة الدراسة.

\subsubsection{1 ماهية الاستدامة البيئية}

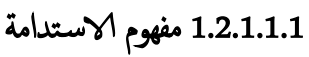
يبين (عوينان، 2008: 26) انه يتم تعريف الاستدامة من خلال ابعاده الاساسية المكونة منها، حيث قدم معهد الموارد العلمية مفوما للاستدامة ضمن اربع مموعات وهي كالاتي

البعد الإقتصادي: يركز مفهوم الاستدامة وفق هذا البعد على الإدارة المثلى للموارد الطبيعية وذلك كما يلي: الاستدامة هو "إستخدام الموارد اليوم ينبغي ألا يقلل من الدخل الحقيقي في المستقبل" ،وأيضا " هو الحصول على الحد الأقصى من المنافع التنمية الإقتصادية بشرط المحافظة على خدمات الموارد الطبيعية ونوعيتها." البعد الإجتاعي والإنساني: الاستدامة تعني " السعي من أجل إستقرار النمو السكاني ورفع مستوى الخدمات الصحية والتعلمة." الاربعة لدى (Mintzberg) نُكون عملية التخطيط الاستراتيحي.

- البعد الثالث: التخطيط اجراء رسمي ونتيجة محددة.

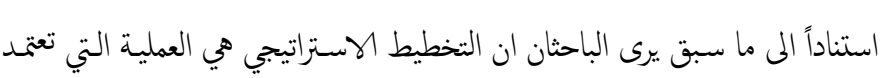
على التبصر- بوضع المنظمة مستثقلاً وبيـان كيفية تحقيق الغايات الاستراتيجية مـن خلال رسم خريطة تفصيلية للمسار المستقبلي للمنظمة ولاجراءات التي تنوي اتباعها في تنفيـذ رسالتها، ويأخذ هـذا التخطيط الاستراتيجي في الاعتبـار جميع المتغيرّات الخارجيّة والداخليّة.

\subsubsection{1 اهمية التخطيط الاستراتيجي}

من الطبيعة الديناميكية للانشطة تبين اهية التخطيط الهسترايي نظرا لانه يمكن المدير من موابجة المستقبل والتغير ولكن لا يككن لاي فرد حتى ولو كان مـديرا ان يكون متاكدا من الاحداث المستقبلية، ويزداد عدم التأكد كلما طالت الفترة الزمنية التي تغطيها الخطط، ولكن التخطيط الاستراتيجي يجبر المدير على تحديدنماذج للاعال المقترحة على ضوء الفروض المتعقة بالمستقبل وعن طريق جهوده الرقابية يقوم المدير دوريا بمراجعة الخطة وتيمها وتعديلها ان لزم الامر وذلك على ضـوء التطورات التي قد تحدث في المجال المعين، وعلى ضوء مـا سبق يحدد (السكارنة، 2010: 38) اربعة اسباب للاهية البالغة للتخطيط الاستراتيجي وهي:

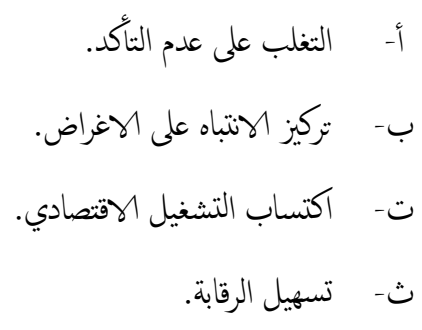
وتكمن اهمية التخطيط الاستراتيجي في النقاط الآتية (المبارك، 2006: 8): توفير الإطار العام للتخطيط التفصيلي وللقرارات التشغيلية. توجيه الموارد والطاقات الأكثر أهمية تجاه العمليات والأنشطة ذات الأولوية المتقدمة. 
من خلال البحث التي قام بها الباحث حول ابعاد التنمية المستديمة تبين ان هناك اتففق بين الكناب والباحثين نهم عبد الجليل، 2014: 218) و (عوينات، 2008) و

$$
\text { (مسعودي، 2009) حول هذه الابعاد والمتمثلة في الاتي: }
$$

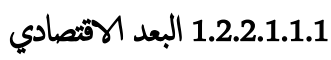

النظام الاقتصادي المستدام هو النظام الذي يسمح بإنتاج السلع والخدمات لإنشباع الحاجات الإنسانية وتحقيق الرفاهية بشكل مستمر دون أن يؤدي ذلك إلى الإضرار بالبيئة الطبيعة، وهذا يفرض تغيير أنماط الإنتاج والاستهلاك للحد من هدر الموارد الطبيعة، والبحث عن الأساليب الفعالة لتلبية الحاجات الاقتصادية دون الإضرار بالبيئة للتقليل من تلوث الهواء، والمياه، والتربة وبالتقليل قدر الإمكان من النفايات السائلة والصلبة أو معالجتها لتفادي آثارها الملمثة للمياه السطحية والجوفية، والتزبة، وما قد ينجم عن ذلك من أمراض وأوبئة (عبد الجليل، 2014: 218). يعتبر البعد الاقتصادي بمثابة الهدف التي يجب الوصول إلها بتحسين الظروف الإقتصادية وذلك لن يتم إلا بإستخدام العقلاني للموارد المتاحة، من أجل الوصول إلى تلى رفاهية متزايدة لأفراد المجتع بالإضافة إلى إيقاف تبديد الموارد الطبيعية: وذلك من خلال إجراء تخفيضات متواصلة من مستويات الإستهلاك المبددة للطاقة والموارد الطبيعة، بالإضافة إلى تغير أنماط الإستهلاك التي تهدد التنوع البيولوجي، والمساواة في توزيع الموارد (عوينان، 2008: 26).

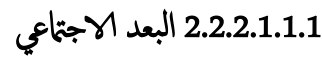

يشمل هذا البعد تحقيق الأهداف الاجتاعية مركزا على الاعتبارات الإنسانية، والإنسان، إذ هو عامل التنمية وهدفها، مثثلا ذلك في تحتيق العدالة الاجتاعية ومكافحة الفقر وبتقديم الخدمات الاجتماعية وغيرها، يضاف إلى هذا تفيل دور المرأة في التربية والتعليم والمشاركة ،وأيضا الاهتام بالطفولة المشردة، وتعتبر التنمية المستدامة النمو وسيلة للالتحام الاجتاعي ولعملية التطوير في الاختيار السياسي، فالهدف العام هو تحقيق مفهوم الإنصاف بين الجمتمعات والأفراد (مسعودي، 2009: 12). وتعني الاستدامة في بعدها الاجتاعي توزيع الثزوة بين أفراد الثجتع وايصال الخدمات الضرورية كالصحة والتعليم والسكن إلى الفئات الفقيرة، والقضاء على الفوارق الاقتصادية والاجتمية بين سكان الأرياف والمدن، والمساواة في النوع الاجتماعي واتاحة المشاركة السياسية ومشاورة هؤلاء السكان في اتخاذ القرارات لإثشاعة الحرية وتطبيق الديمقراطية. كما ينبني أن يكون النمو الديكرافي في أي بلد معقولا ومتوازنا مع
البعد البيئي: الاستدامة تعني حاية الموارد الطبيعية والإستخدام الأمثل للأرض

\section{الزراعية والموارد المائية.}

البعد التكنولوجي: الاستدامة تعني نقل الجمتعع إلى عصر الصناعات النظيفة التي

$$
\text { تستخدم تكنولوجيا منظفة للبيئة، وتنجج الحد الأدنى من الغازات الملمثة. }
$$

وقد عرفت اللجنة العالمية للتنمية والبيئة الاستدامة بأنها التنمية التي تأخذ بعين الاعتبار حاجات البجتمع الراهنة بدون المساس بحقوق الأجيال القادمة في الوفاء باحتياجنهم (ديب وهنا، 2009: 488). ويرى البعض أن التنمية المستدامة تقوم على لى مبادئ أساسية تتمثل في تبني أنماط إنتاج واستهلاك تحترم البيئة الطبيعية والإنسانية، وتسمح لجميع سكان الأرض بتلبية حاجاتهم الأساسية الغذاء، السكن، اللباس، التعليم، العمل والعيش في بيئة سليمة (عبد الجليل، 2014: 217). والشكل (1) يوضح مفهوم الاستدامة الناتج من تقاطع ثلاثة ابعاد ( المرغوبة اجتاعيا, الملائمة اقتصاديا , والفعالة بيئا), وبسبب مخاوف علماء الاقتصاد والاجتماع والبيئة

Broose, 2011: مكتتم من جلب تقاطع حلول الاستدامة قابلة للانجاز في المجتع (Wright \& 17)

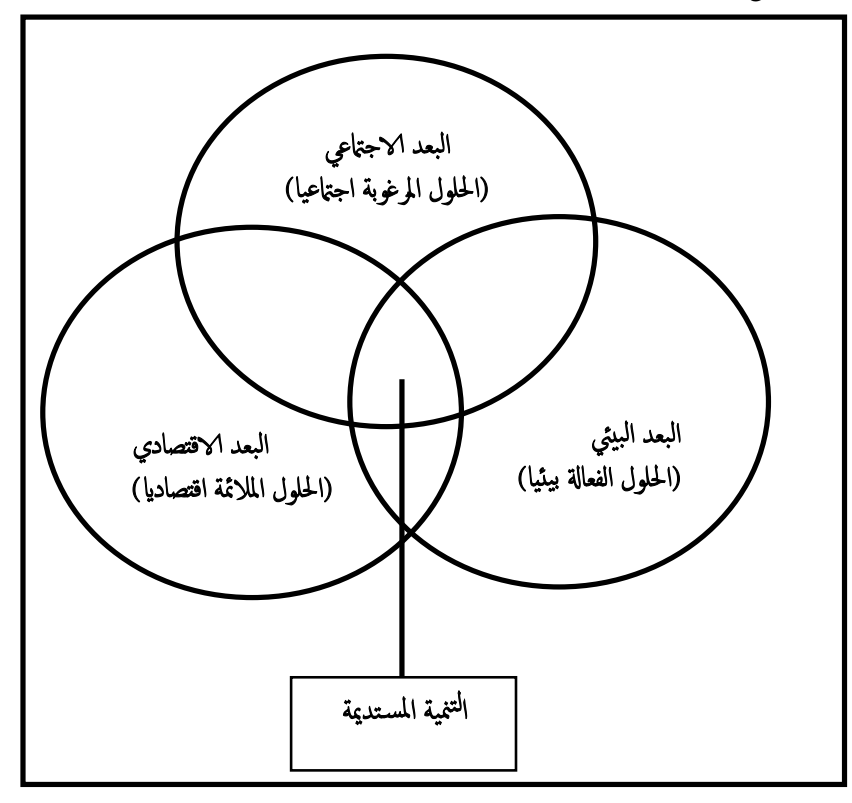

Source: Wright, Richard T.\& Boorse, Dorothy F.,2011", Environmental Science", $7^{\text {th }}$ Ed, pearson Benjamin eummings: P.17.

الشكل 1. مفهوم التنمية المستديمة

2.2.1.1.1 ابعاد الاستدامة (التنمية المستدامة). 


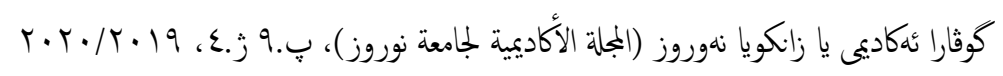
إمكانات حكومة كل بلد ومواردها الطبيعة،لأن أي زيادة ديمرافية سريعة وغير متوازنة تجعل الحكومة غير قادرة على تلبية حاجات سكانها من الخدمات الضرورية في مجال الصحة، السكن، التعليم مما قد يؤدي إلى ت ا زيد عدد الفقراء ومن ثم استغلال

المصدر: محمد، انس ساتي ساتي، (2014)، قراءات حول فلسفة التنمية المستدامة، مجلة الدراسات المالية والمصرفية،

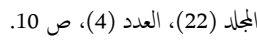

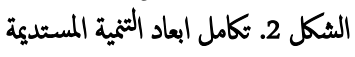

\subsubsection{1 مفهوم الاستدامة البيئية}

تعتبر الاستدامة البيئية أحد الأبعاد الأساسية وقيمة محورية من مضامين ومتطلبات التنمية المستدامة فهي تعنى بوحدة الأظظمة الحيوية والقدرة على التجمل والاستيعاب والحفاظ على الموارد الطبيعة شاملة التنوع البيولوجي (منصوري ورمزي، 2008: 2). انها تعني القدرة على المحافظة على أصول ذات القيمة بيئيا على مدى العقود القليلة Siche, et al, 2007: ( القادمة وإدارة المشاكل التي تنشأ من الظروف البيئية المتغيرة 3). هي الحفاظ على رأس المال الطبيعي (Morelli, 2011:1). ويؤكد ( Menzies) انه حتى نعرف الاستدامة البيئية ينبني النظر في الرفاهية وكفاوة استخدام الطاقة في وقت واحد، والاستدامة البيئية هي تلبية الاحتياجات الحالية من خلال الاستخدام المسؤول للموارد، وتمكين الأجيال القادمة

$$
\text { على توفير احتياجاتهم. }
$$

ويعرف (Morelli, 2011: 5) الاستدامة البيئية بانه حالة من التوازن والمرونة والترابط الذي يسمح الجمتع البشري لتلبية احتياجاتها بينها لا تتجاوز قدرة النظم الإيكولوجية التي تدع مواصلة تجديد الخدمات اللازمة لتبية تلك الهتياجات. تفرض الاستدامة البيئية ضرورة المحافظة على قاعدة ثابتة من الموارد الطبيعية بإتباع أنماط إنتاج واستغلال للموارد الطبيعية بشكل عقلاني لتجنب الاستنزاف الزائد للموارد المتجددة وغير المتجددة، لضمان التنوع الحيوي، ونقاء الهواء وخصوبة التربة والمحافظة على التنوع البيولوجي، ويركز المختصون في مجال البيئة في مقاربته للاستدامة البيئية على مفهوم" الحدود البيئية "التي تعني أن كل نظام طبيعي حدودا لا يكن تجاوزها من الاستغلال وأن إفراط استغلال هذه الموارد يعني تدهور النظام البيئي، والسبيل الوحيد لمحاية هذا النظام هو الحد من إنباع أنماط الإنتاج والاستهلاك السيئة، مثل استنزاف المياه الجوفية والسطحية، وقطع أشجار الغابات وغيرها (عبد الجليل، 2014: - (2019) - (219). الثروات والموارد الطبيعية من مياه وارض ز ا رعية بطرق عشوائية تستنزف هذه الموارد وتعيق استدامة النتمية وتثقل كاهل الأجيال القادمة (عبد الجليل، 2014:

3.2.2.1.1.1 البعد البيئي وهو منشأ هذا المفهوم، ويتعلق بالحفاظ على قاعدة الموارد المادية والبيولوجية، وعلى النظم الإيكولوجية وتعزيز حهيتها وترشيدها ، ويشمل هذا البعد الاهداف الاتية (عوينان، 2008: 26): حاية الموارد الطبيعية :ابتدا من حلية التربة إلى حاية الأراضي المخصصة

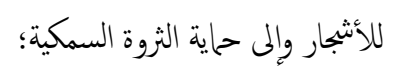
حاية المناخ من الإحتباس الحراري: عدم المخاطرة بإجراء تغيرات كيرة في البيئة العالمية بزيادة مستوى سطح البحر أو تغير أنماط سقوط الأمطار أو زيادة الأشعة فوق البنفسجية، ويعني ذلك بكري الحيلولة دون زعزعة استقرار المناخ أو تدمير طبقة الأزون الحامية للأرض من جراء أفعال الإنسان. هناك علاقات تفاعلية متداخلة بين ابعاد التنمية المستديمة، ويؤكد (عبد الجليل، 2014: 219) على ذلك، اذ يرى ان أن إغفال البعد الاجتاعي أو البيئي يؤثر سلبا على البعد الاقتصادي. وفي هذا السياق يؤكد (Károly, 2011:2) على تكمل ابعاد الاستدامة، اذ يشر الى ان الاستدامة لن يتحقق اذا كان الاداء الاقتصادي غير صحيح، واذا لم يتم حل المشاكل الاجتماعية الاساسية. ويؤكد (محم، 2014: 9) ان التنمية المستدامة لا تركز على الجانب البيئي فقط بل تشمل أيضا الجوانب الاقتصادية والاجتاعية وبالتالي فهي تنمية ثلاثية الأبعاد (متزابطة ومتكاملة ومتداخلة) في إطار تفاعل يتسم بالضبط والتنظير والترشيد للموارد

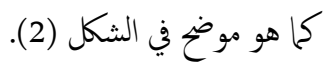

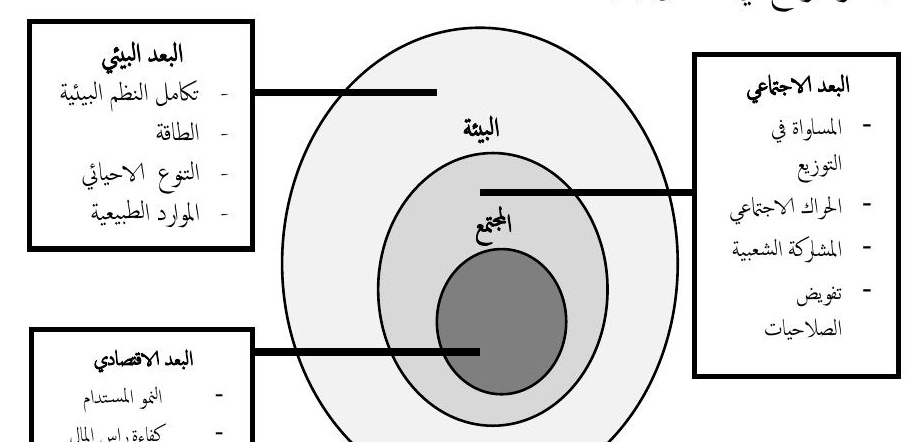




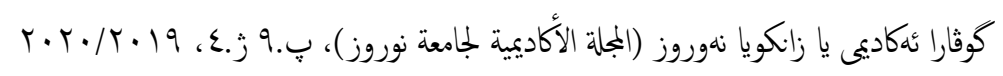

Source: Pogutz, Stefano; Micale, Valerio; and Winn, Monika (2011) "Corporate Environmental Sustainability Beyond Organizational Boundaries: Market Growth, Ecosystems Complexity and Supply Chain Structure as Co-Determinants of Environmental Impact, Journal of Environmental Sustainability: Vol. 1: Iss. 1, Article 4, $\mathrm{P} 12$.

\section{الشكل 3 .السيناريوهات الأربعة للاستدامة البيئية}

ويسلط (Gamage and Abeysinghe, 2008: 3) الضوء على أهمية الاستدامة البيئية للشركة، اذ يؤكد أن الاستدامة البيئية تتطلب إنشاء العمليات والأنظمة التنظيمة الجديدة، و أن تكون موجهة نحو خلق نظم الإنتاج الخضراء، وتعد استراتيجيات السوق المحرك الأول لالتقاط الأسواق الخضراء، وتتطلب هياكل فعالة من حيث التكلفة من الناحية البيئية الناشئة لتحقيق الأرباح على المدى الطويل، وتوفر نظام قانوني بشأن الانتامات البيئية ومسؤوليات الانتاج، ووجود برامج

$$
\text { لتحسين العلاقات العامة وصورة الجمتح. }
$$

بالاستناد المى ما سبق يرى الباحث ان التنمية المستدامة تعبر عن تلبي حاجات المجتمع الراهنة من دون المس بما يقدر عليه الأجيال القادمة من أجل الوصول إلى أهدافهم كما أنهّا تركزّ بدور كبير على النمو الاقتصادي المتكامل.

\subsubsection{1 استراتيجيات الاستدامة البينية:}

تتضمن إستراتيجية الاستدامة البيئية أعحال معتمدة في تلبية الحاجات الحالية للزبائن, والمجزين, والمساهين, والعاملين, وأصحاب المصاح الآخرين في الأسلوب الذي يحمي البيئة, ويزيد من الموارد الطبيعية مدى الحياة والابقاء على أنظمة الدع للأجيال المستقبلية والحذر من المخاطر النهائية المحيطة بالكون، ويجب على المنظلات المستنيرة ان لا تأخذ الاعهال فقط، أو الحصول على الأرباح قصيرة المدى ,ولكن الاخذ بعمل

$$
\text { الاشياء الصحيحة لمستقبل المنظمة والكون البيئي. }
$$

اذ قام هارت وزملائه في 2003 بتحديد استراتيجيات الاستدامة التي تمكن المنظلات من تحقيق الفرص التي تتيحها او تقدها الاستدامة البيئة، وتشمل هذه الاستراتيجيات الاتي (Thambusamy \& Salam, 2010:4):

\subsection{1}

هو استراتيجية الاستدامة البيئية التي تزكز على "تحسين الكفاءة البيئية للمنتجات

$$
\text { وعمليات اليوم للحد من النفايات والانبعاثات الناتجة عن العمليات الجارية". }
$$

نجد ان استراتيجية منع التلوث تعني قيام المصنع بفصل الملوثات أو ترسيها قبل انطلاقها إلى الوسط الميط، وامتلاك أبجزة متخصصة لقياس جم التلوث ووضع
ومن الناحية العملية، فإن "الاستدامة البيئية" يشير إلى وجود عملية التخطيط التي Basiago, ) المسمح المتمع البشري إلى "العش في حدود البيئة الفيزيائية الحيوية 156 :1999). وتتضمن الاستدامة البيئية خمسة ابعاد هي: ( :Siche, et al, 2007

$$
\text { - - - - الضظم البيئية (الهواء، والماء، والارض، والتنوع البيولوجي). }
$$

- القدرات المؤسسية والاجتاعية: القدرات التي تسمح التعامل مع المثاكل

$$
\text { والتحديات البيئية. }
$$

- م الاشراف/ المتابعة العالمية: (جهود ومشاريع تمثيلية للتعاون الدولي من المسؤولية

اما الاستدامة البيئية للشركة (على مستوى الشركة) فانها تشير إلى قدرة الشركة على الإدارة الفعالة والسيطرة على الأضرار التي لحقت بالبيئة الطبيعية من خلال

\begin{tabular}{|c|c|}
\hline 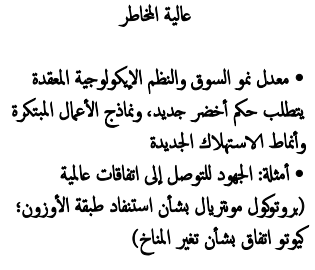 & 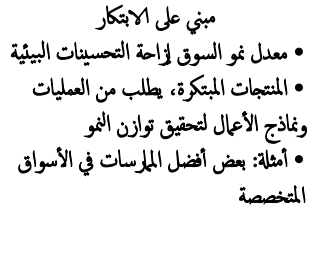 \\
\hline 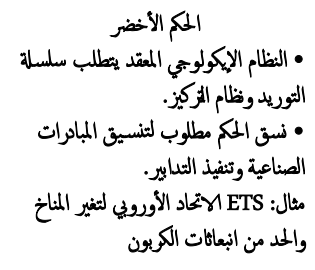 & 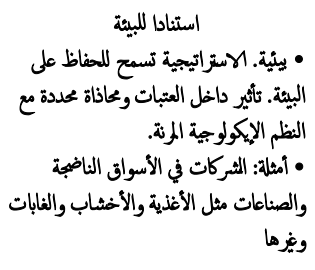 \\
\hline
\end{tabular}
عogutz, Micale and Winn, ) عملياتها ومنتجاتها والأنشطة التجارية الهخى 9 :2011). كما ان النقاش الواسع حول تأثير الشركات في البيئة الطبيعية وبحت العلماء والممارسين في محاولة لتعريف الاستدامة البيئية للشركة، وفي هذا السياق يقدم (Pogutz, Micale and Winn, 2011:12) مصفوفة ذو بعدين (نو السوق وادارة تاثير البيئة) لتوضيح سيناريوهات الاستدامة البيئية للشركة، والشكل الاتي يوضح ذلك: 


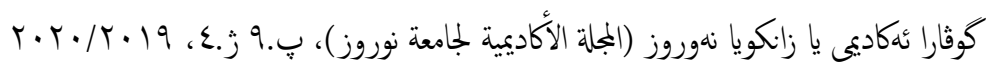

ويشير (Thambusamy \& Salam, 2010:4) الى انه يكن للمنظات تحقيق الاستدامة وتثيت استجاتهم البيئية عن طريق استخدام رؤية الاستدامة لدمج استراتيجيات الاستدامة البيئية المتمثلة في (منع التلوث، ورقابة على المنتجات والتقنية Kotler \& Armstrong, النظيفة) في استراتيجية الشركة الخاصة بهم. ويقدم 2011 مصفوفة لتلك المنظات التي يمكن أن تقيس تقدها تجاه الاستدامة البيئية, وتتضمن المصفوفة بيئة داخلية وبيئة خارجية وأننطة التخضير التي ستدفع بالمنظمة من الانتقال من الاعتماد على الانشطة قصيرة المدى إلى الاعتماد على أنشطة ما وراء التخضير في المدى البعيد, فني المستوى الوول للمصفوفة يتطلب من المنظمة أن تعمل على منع النلوث أو إزالنه وتقليل النفايات قبل نشؤها, أما بالنسبة للمستوى الثاني فهو تطوير التكنولوجيا النظيفة وتطوير جموعات جديدة من المهارات والقابليات البيئية, في حين ينبغني على المستوى الثالث إدارة المنتج, وهذا يعني تقليل الثاثثير البيئي من خلال المنتج في جميع مراحل دورة حياته, أما المستوى الأخير فهو الرؤية Kotler \& ) المستدامة اي خلق هيكل استراتيجي للاستدامة في المستقبل (Armstrong ,2011: 552

\begin{tabular}{|c|c|c|}
\hline \multirow[b]{3}{*}{ عوامل داخلية } & اليوم ( التخضير) & خدا (ما وراء التخضير) \\
\hline & منع التلوث & تكنولوجيا نظيفة جديدة \\
\hline & إزالة وتقكليل النفيات قبل & تطوير مجموعة جديدة \\
\hline \multirow{4}{*}{ عوامل خارجية } & أن تششأ & للمهارات والثقابليات البينية \\
\hline & إدارة المنتج & روية مستدامة \\
\hline & تخفيض التاثير البيني في & خلق هيكل إستراتيجي \\
\hline & جميع أنحاء دورة حياة المنتج & كلاستكامة في المستقبل \\
\hline
\end{tabular}

Source: Kotler, Philip\&Armstrong, Gary,2011,"Marketing",10 $10^{\text {th }} E d$, prentice -Hall:P.552

شكل 4. الاستدامة البينية

2.1

ويجتوي على

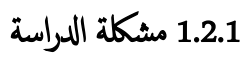

أصبحت البيئة عاملا محا في عملية صنع القرار للمنظات في جميع أنحاء العالم بما في ذلك الدول الاقل تقدما. واصبحت القضايا البيئية أكثر تعقيدا وترابطا. وهناك ردود افعال قوية على الطرق التقليدية لمعالجة القضايا البيئية، اذي يتطلب الاهر من المنظلات العمل على تبني استراتيجيات الاستدامة البيئية من اجل تحسين ادائها وفق المنظور البيئي. وعلى هذا يمكن توضيح مشكلة الدراسة من خلال التساؤلات الاتية:
الحول المناسبة لها، والعمل على نشر الثقافة والوعي الذاتي بين العاملين بالخاطر التي

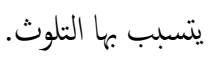

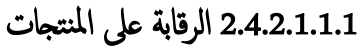
تشمل "دورة حياة المنتج بأمكلها، ابتداء من وصول المواد الخام، مرورا بعمليات الإنتاج، واستخدام المنتج والتخلص من المنتجات الهالكة".

وتعني استراتيجية الرقابة على المنتجات اعتاد ادارة المصنع مواد غير ملوثة عبر دراسة خصائص مكونات المواد الاولية التي تستخدما، وتخصص جزءا من ايراداتها لانشطة البحث والتطوير لغرض استبدال المواد الاولية الخطرة التي تستخدها، وتوظيف استراتيجية تقلل من المخلفات في كافة مراحل عملياتها الانتاجية، والعمل ايقاف اية عملية انتاجية التي تنبعث منها نسبة غازات عالية، والتخلص من المنتجات الهالكة حسب القوانين والنعلمات الخاصة بحاية البيئية من التلوث.

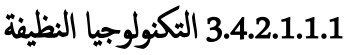

تشير الى " الابتكرات التي تخطي الروتينية القياسية والمعرفة بالاضافة الى التحسن

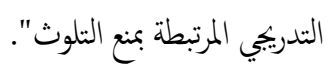

وتشير استراتيجية النكنولوجيا النظيفة المى استثار المصنع التقنيات التي تؤمن لها الوصول الى افضل السلع وتلافيا لأي اثار سلبية لعمليات انتاجما، وتغيير التقنيات عند ارتفاع معدلات استهلاك الطاقة التي تستخدم فيها، وتطوير وسائل الإنتاج باستمرار من خلال إدخال تقنيات حديثة اقل إحداثا للتلوث، واستخدام المرشحات والمرسبات الكهربائية والوسائل الميكانيكية الأخرى كالأبراج ومعدات الاحتراق الخاصة وغيرها حيث تنناسب مع طبيعة الملوثات المنطلقة والمطلوب التحكي فيها.

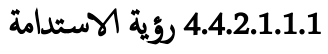
تتمثل هذه الاستراتيجية في قدرة الشركات على تطوير أسلوبها في التعامل والتخطيط لتلبية احتياجات الاستدامة البيئية المستقبلية. يجد الباحث ان رؤية الاستدامة تنتثل في امتلاك المصنع رؤية واضحة عن التوجه نحو الاستدامة البيئية في المستقبل، والقدرة على التعامل مع القضايا البيئية التي توابته، والعمل على توفير الطاقة والحد من استنزاف الموارد الطبيعية والحفاظ عليها لتحقيق الاستدامة من اولويات التخطيط البيئي للمصنع، والايمان بانه لا يكن تحقيق التنمية على قاعدة تتدهور فيها الموارد الطبيعية. 
تصيميمها للأنموذج هـذا على مؤشرات التخطيط الاستراتيجي المتمثلة في (التوجه الاستراتيجي، والتحليل البيئي، وصياغة وتطبيق الاستراتيجية، والتقويم) التي تمثل المتغير المستقل. اما المتغير التابع فتمثل في استراتيجيات الاستدامة البيئية والمتمثلة في (منع التلوث، والرقابة على الانتاج، والتكنولوجيا النظيفة والرؤية المستدامة).

المصدر: من إعداد الباحثين

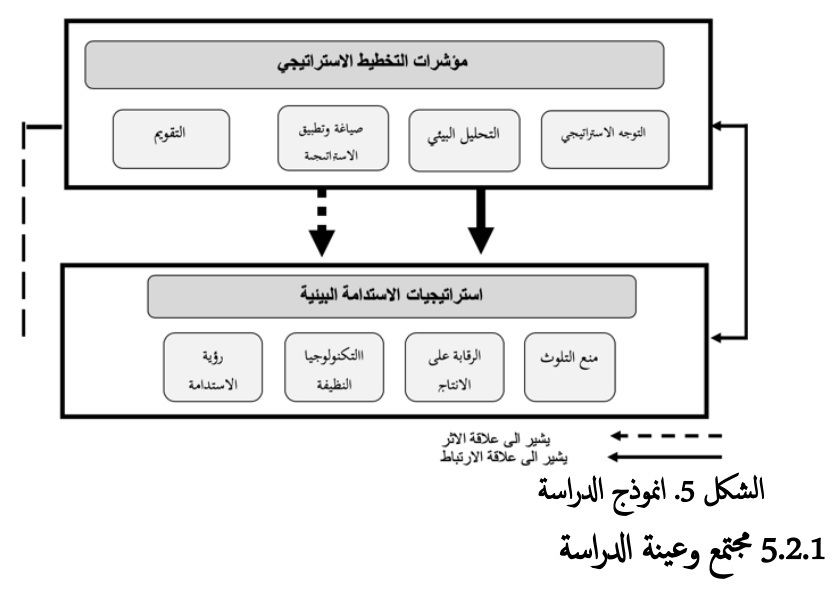

يتمثل مجتع الدراسة بمجموع مصانع المياه المعدنية والبالغ عددها (8) مصنع لغاية 1\3|2018، وقد اختير هذه القطاع ليكون ميداناً لإجراء الدراسة الحالية لإمكانية

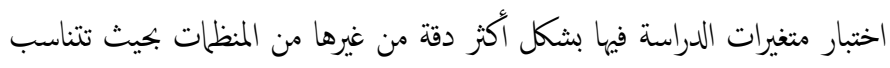
وأهداف الدراسة الحالية. وتم تحديد (50\%) من هذه المصانع لنكون عينة للدراسة؛ أي ان عدد المصانع التي طبقت الدراسة فيها بلغ (4) تم اختيار هم بشكل غير عشوائي، اما الافراد المبحوثون فتمثل بالقيادات الادارية المتمثلة بمسؤولي الوحدات حصراً وذلك بك راجع إلى انه هم المطلعون على الامور التي تخدم اهداف الدراسة. وتم القيام بتوزيع استمارة الاستبانة على الافراد المبحوثين في الثركات المبحوثة المبحوثة وقد بلغ عددها (45) استمارة اعيد منها (31) صالحة للتحليل أي أن سبة الاستجابة كانت (68.8\%)، ويوضح الجدول الاتي توزيع الأفراد المبحوثين وفقا لخصائصهم الفردية.

\section{الجدول (4)}

\begin{tabular}{|c|c|c|c|c|}
\hline النسبة & |العدد & الفئات & الخصائص & ت \\
\hline 29 & 9 & اقل من (35) سنة & العمر & 1 \\
\hline 48.4 & 15 & $(45)-(35)$ & & \\
\hline 22.6 & 7 & اكثر من (45) & & \\
\hline 100 & 31 & الجموع & & \\
\hline 90.3 & 28 & ذك & الجنس & 2 \\
\hline 9.7 & 3 & انثى & & \\
\hline 100 & 31 & المجموع & & \\
\hline
\end{tabular}

هل هناك تصور واضح عن التخطيط الاستراتيجي ومؤشراته في الشركات قيد

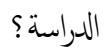

هل هناك تصور واضح عن ماهية الاستدامة البيئة واستراتيجياتها في الشركات قيد

الدراسة؟

هل هناك علاقة ارتباط معنوية بين التخطيط الاستراتيجي واستراتيجيات الاستدامة البيئية في الشركات قيد الدراسة؟ هل هناك تاثير معنوي للتخطيط الاستراتيجي في استراتيجيات الاستدامة البيئية

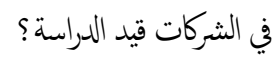

\subsection{1 أهداف الدراسة}

تهدف الدراسة الحالية المى تحقيق هدف أساسي وهو تحديد علاقات الارتباط والتأثير بين التخطيط الاستراتيجي واستراتيجيات الاستدامة البيئية في الثركات قيد الدراسة، وتأكيداً على هذا الهدف الرئيسي فإن هذه الدراسة تسعى إلى تحقيق ما يأتي: أ. وصف وتشخيص مؤشرات التخطيط الاستراتيجي واستراتيجيات الاستدامة البيئة.

ب. التعرف على طبيعة الارتباط بين التخطيط الاستراتيجي واستراتيجيات الاستدامة البيئية في الثركات قيد الدراسة.

ت. التعرف على الدور التأثري للتخطيط الاستراتيجي في استراتيجيات الاستدامة البيئية في الشركات قيد الدراسة.

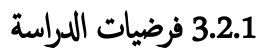

توافقاً مع أهداف الدراسة واختباراً لأموذجما فقد اعتمدت الدراسة على الفرضيات الآتية: أ. الفرضية الرئيسة الأولى: هناك علاقة ارتباط معنوية بين التخطيط الاستراتيجي واستراتيجيات الاستدامة البيئية، وتنبثق عنها بمحوعة من الفرضيات الفرعية. ب. الفرضـية الرئيسـة الثانيـة: هنـاك تـأثير معنـوي للتخطيط الاسـتراتيجي في استراتيجيات الاستدامة البيئية، وتنثق عنها بموعة من الفرضيات الفرعية.

\subsection{1 خخطط المراسة}

تستلزم المعالجة المنهجية لمشكلة الدراسة في ضوء إطارها النظري تصميم أنموذج فرضي كما هو موضح في الشكل (5) والذي يصور علاقة الارتباط والاثر بين التخطيط الاستراتيجي واستراتيجيات الاسـتدامة البيئية في الشركات المبحوثة والتي تثبـت تحقيقه من عدمه وفق نتائُ تحليل الاختبارات الاحصائية. ولقد اعتمد الباحثان في 


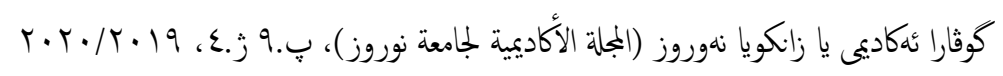

الحدود الزمانية: امتدت الحدود الزمانية للدراسة للفترة بين (2017/11/1)

$$
\text { ولغاية (2018/3/20). }
$$

- - ملحدود المكلنة: تمثل الحدود المكانية للدراسة بالمصانع التي تم تطبيق الدراسة عليها.

الحدود الموضوعية: تتمثل في التخطيط الاستراتيجي واستراتيجيات الاستدامة البيئية.

\begin{tabular}{|c|c|c|c|c|}
\hline & & شهادة عليا & 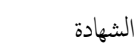 & 3 \\
\hline 51.6 & 16 & بكلورويس & & \\
\hline 35.4 & 11 & اعدادية & & \\
\hline 13 & 4 & متوسطة فا دون & & \\
\hline 100 & 31 & الجموع & & \\
\hline 19.4 & 6 & بالمركز اقل من 3 سنوات & مدة الخدمة & 4 \\
\hline 54.8 & 17 & 7-3 سنوات & الوظيفي الحالي & \\
\hline 25.8 & 8 & اكثر من 7 سنوات & & \\
\hline 100 & 31 & الجموع & & \\
\hline
\end{tabular}

تم جمع البيانات من مصادرها الاولية والثانوية، اذ اعتمدت الدراسة على جمع البيانات

من المصادر الأولية لتغطية الإطار العملي للدراسة من خلال استخدام اسلوب الاستبانة1 التي تم تصميم متغيراتها بالاستفادة من دراسات (الجبوري، 2011) و(الزهيري، 2010)، فضلاً عن وضع بعض الاسئة المستمدة من استراتيجيات الاستدامة البيئة مع الأخذ بنظر الاعتبار بيئة المصانع قيد الدراسة. بينها اعتمت الدراسة على ما مناح من الكنب، والابحاث المنشورة، والدوريات في بناء الإطار النظري للدراسة من مصادرها الثانوية. 7.2.1 أساليب التحليل الاحصائي للبيانات والتكنولوجيا النظيفة، ورؤية الاستدامة) ويظهر الملحق (2) التوزيعات النكرارية وقيم الوسط الحسابي والانحراف المعياري وعلى مستوى العينة قيد الدراسة، وفيم يأتي تحليلها:

من أجل التوصل إلى مؤشرات دقيقة تخدم الدراسة الحالية ومن أجل اختبار فرضياتها

1.1.2 مؤشرات التخطيط الاستراتيجي: أ. التوجه الاستراتيجي: تشير النتائُ الواردة في الملحق (2) الى ان اجابات المبحوثين حول هذا البعد من خلال مؤشراته (X19-X1) تميل باتجاه الاتفاق وبنسبة (65.59\%) من تلك الاجابات، وبوسط حسابي (3.77) وانحراف معياري (0.733)، في حين بلغت نسبة عدم الاتفاق على مؤشرات هذا البعد سبة (4.30\%)، وجاء هذا الاتفاق بمستويات استجابة جيدة ما يعطي دلالة اولية على ان آراء افراد العينة تجاه التوجه الاستراتيجي تشير الى الإطار الذي يوفر للثركات قيد الدراسة المحاية لاستثمار مواردها فضلاً عن إيجاد رؤية مناسبة للمدراء تحقق لمم المرونة في التكيف مع متغيرات البيئة وموابتهنا وفق رسالة تسترشد الاهداف الاستراتيجية للمنظمة. وإن اعلى نسبة اتفاق كانت على المؤشر (X6) اذ بلغت نسبة الاتفاق (83.8\%)، وبوسط حسابي (4.10) وانحراف معياري مقداره (0.746)، مما يدل على ان المصنع يعمل على

\section{فقد اعتمدت الدراسة بموعة من الأساليب الإحصائية تتمثل في الآتي:}

النسب المئوية والتكرارات والمتوسطات الحسابية والانخرافات المعيارية من أجل

\section{وصف متغيرات الدراسة وتشخيصها.}

معامل الارتباط البسيط لتحديد قوة وطبيعة العلاقة بين متغيرات الدراسة.

الإنحدار الخطي البسيط لقياس التأثير المعنوي للمتغيرات المستقلة في المتغير

التنابع.

وقد تم استخدام برنامج (SPSS: V. 12) الإحصائي في إيجاد التوزيعات التكرارية واستخراجما والوسط الحسابي والانحراف المعياري، فضلاً عن إيجاد ننائُ الاتباط والانحدار.

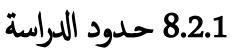
يككن تقسيم حدود الدراسة إلى حدود زمانية ومكانية:

1 استارة الحستبانة موضحة في الملدق (1). 


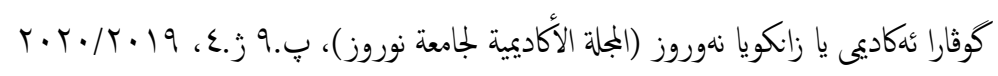

من خلالها إلى وضع بموعة من الحلول الممكنة والتي على أساسها يتم اختيار الحل الذي تراه المناسب، ومن خلال متابعة مدى اسهام كل فقرة تبين ان الشركات قيد الدراسة بهيئ الافراد في جميع المستويات والقادرين على تنفيذ التخطيط الاستراتيجي (x20) هو الاكثر اسهاما اذ حظي ذلك باتفاق (\%64.5) من المبحوثين وبوسط حسابي مقداره (3.65) وانحراف معياري (0.985). في حين برز ضعف الاتغاق حول فقرة (x17) اذ بلغت نسبة الاتفاق (45.1\%) وبوسط حسابي (3.42) وانحراف معياري (1.025) مما يعني ان الشركات قيد الدراسة لا يسعون لصياغة الاستراتيجيات التي تحقت الموائمة بين مواردها وقدراتها الداخلية من جحة ومتطلبات البيئة المارجية من بجة

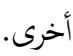
الثقويم: تشير معطيات الملحق (2) المى التوزيعات التكرارية وقيم الوسط الحسابي والانحراف المعياري تجاه العبارات (X17 - X20) الخاصة بمؤشر صياغة وتطبيق الاستراتيجية، والتي تؤكد اتفاق الافراد المبحوثين على هذه العبارات، اذ بلغ نبة الاتفاق (52.43\%) مقابل عدم اتفاق (9.7\%) والنسبة المتبقية منهم (37.9\%) محايدون، وجاء ذلك بوسط حسابي (3.50) وانخراف معياري (0.772)، وجاء هذا الاتفاق بمستويات استجابة مقبولة ما يعطي دلالة اولية على ان آراء افراد العينة تجاه التقويم الاستراتيجي تشير الى عمليات تتم لتتبع ورقابة أنشطة المنظمة ونتائُ أدائها الفعلي فى مقابل الأداء المرغوب أو الخخطط. وقد تظهر نواحي ضعف فى تنفيذ الاستراتيجية ومن ثم تحث العمليات فى المنظمة كلها على البدء من جديد مرة ثانية. ومن خلال متابعة مدى اسهام كل فقرة تبين ان الشركات قيد الدراسة بهيئ الافراد في جميع المستويات والقادرين على تنفيذ التخطيط الاستراتيجي (x20) هو الاكثر اسهاما اذ حظي ذلك باتفاق (61.3\%) من المبحوثين وبوسط حسابي مقداره (3.55) وانحراف معياري (0.723). في حين برز ضعف الاتفاق حول فقرة (x17) اذ بلغت نسبة الاتفاق (48.4\%) وبوسط حسابي (3.48) وانخراف معياري (0.890) مما يعني ان الشركات قيد الدراسة لا يسعون لصياغة الاستراتيجيات التي تحقق الموائمة بين مواردها وقدراتها الداخلية من بحة ومتطلبات البيئة الخارجية من جهة أخرى.
تطوير العمليات الانتاجية وتحديثا في ضوء الاتجاهات العلمية المعاصرة مع مراعاة الظروف المحلية. في حين كانت اقل نسبة اتفاق لمؤشرات هذا البعد على المؤشر (X1) وهي (51.6\%)، وبلغ الوسط الحسابي للمؤشر (3.48) والاخراف المعياري له (0.677)، مما يدل على ان المصنع يحدد غرضه وطريقة

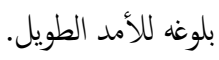
ب. التحليل البيني: تشير معطيات الملحق (2) المى التوزيعات التكرارية وقيم الوسط الحسابي والانخراف المعياري تجاه العبارات (X10 - X16) الخاصة بمؤشر التحليل البيئي، والتي تؤكد اتفاق الافراد المبحوثين هذه العبارات، اذ بلغ نسبة الاتفاق (52.51\%) مقابل عدم اتفاق (11.54\%) والنسبة المتبقية منهم (34.57\%) محايدون، وجاء ذلك بوسط حسابي (3.57) وانحراف معياري (0.899). وجاء هذا الاتفاق بمستويات استجابة مقبولة ما يعطي دلالة اولية على ان آراء افراد العينة تجاه التحليل البيئي تشير الى مراجعة الشركات قيد الدراسة كل ما يتعلق بالبيئة الداخلية والخارجية بهدف التعرف على اهم نقاط القوة والضعف الداخلية والفرص والتهديدات الخارجية. ومن خلال متابعة مدى لته اسهامكل فقرة في التحليل البيئي تبين ان وجود مصانع للمياه المعدنية في مدينة دهوك يؤثر علالثركات قيد الدراسة (x16) هو الاكثر اسهاما اذ حظي ذلك باتفاق (61.3\%) من المبحوثين وبوسط حسابي مقداره (3.61) وانحراف معياري (0.955). في حين برز ضعف الاتفاق حول مراعاة الشركات قيد الدراسة مواكبة التطور التكنولوجي (x14) اذ بلغت نسبة الاتفاق (48.4\%) وبوسط حسابي (3.61) وانخراف معياري (0.919). ج. صياغة وتطبيق الاستراتيجية: تشير معطيات الملحق (2) الى التوزيعات التكرارية وقيم الوسط الحسابي والانحراف المعياري تجاه العبارات (X17 (X20) الخاصة بمؤشر بصياغة وتطبيق الاستراتيجية، والتي تؤكد اتفاق الافراد المبحوثين على هذه العبارات، اذ بلغ نسبة الاتفاق (53.23\%) مقابل عدم اتفاق (16.93\%) والنسبة المتبقية منهم (29.85\%) محايدون، وجاء ذلك بوسط حسابي (3.49) وانحراف معياري (1.046)، وجاء هذا الاتفاق بمستويات استجابة مقبولة ما يعطي دلالة اولية على ان آراء افراد العينة تجاه صياغة البدائل الاستراتيجية تشير رسم الثركات قيد الدراسة لنفسها استراتيجية وذلك على ضوء المتغيرات البيئية الداخلية منها والخارجية والتي تصل 2.1.2 استراتيجيات الاستدامة البيئية 


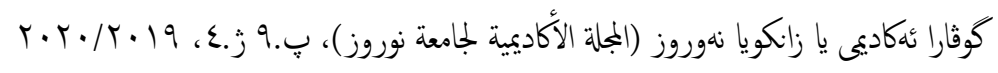

تلك الاجابات، مقابل عدم اتفاق (9.7\%) والنسبة المتبقية منهم (41.1\%) محايدون، وبوسط حسابي (3.41) وانحراف معياري (0.717). وهذا ما يدل على عدم توافر مؤشرات رؤية الاستدامة في الشركات قيد الدراسة بحسب اراء الافراد المبحوثين.

\section{2 تحليل علاقات الارتباط بين متغيرات الدراسة.}

1.2.2 العلاقة بين التخطيط الاستراتيجي واستراتيجيات الاستدامة البيئة على

\section{المستوى الكلي للشركات قيد الدراسة.}

بغية التعرف على طبيعة علاقات الارتباط بين التخطيط الاستراتيجي واستراتيجيات الاستدامة البيئية على مستوى العينة المبحوثة يشير الجدول (5) * إلى وجود علاقة ارتباط معنوية بين التخطيط الاستراتيجي واستراتيجيات الاستدامة البيئية، اذ بلغت درجة الارتباط (المؤشر الكلي) (0.375) وبهذا فقد تحقت الفرضية الرئيسة الأولى. 2.2.2 العلاقة بين التخطيط الاستراتيجي وكل استراتيجية من استراتيجيات الاستدامة البيئة على المستوى الكلي للشركات قيد الدراسة. يشير الجدول (5) الى عدم وجود علاقة ارتباط معنوية بين التخطيط الاستراتيجي وكل استراتيجية من استراتيجيات الاستدامة البيئية. ويتضح من الجدول المذكور إن علاقة ارتباط كانت معنوية فقط بين التخطيط الاستراتيجي واستراتيجية التكنولوجيا النظيفة اذ بلغت درجة الارتباط (المؤشر الكلي) (0.444) وعند مستوى معنوية (0.05). في حين كانت علاقة الارتباط غير معنوية بين بين التخطيط الاستراتيجية واستراتيجية منع التلوث والرقابة على الانتاج ورؤية الاستدامة، وبهذا فان الفرضيات الفرعية المنبثقة من الفرضية الرئيسة الاولى لم يتحقق باستثناء الفرضية الفرعية الثالثة والتي تنص على وجود علاقة ارتباط معنوية بين التخطيط الاستراتيجي واستراتيجية النكنولوجيا النظيفية.

\section{5 الجدول 5}

ثتاجُ علاقات الارتباط بين التخطيط الاستراتيجي واستراتيجيات الاستدامة البيئية على مستوى عينة الدراسة

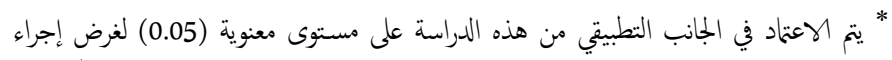

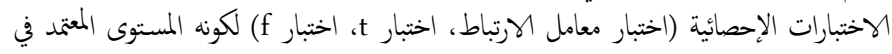
اغلب الدراسات الانسانية.
أ. منع الثلوث: تشير معطيات الملحق (2) الى التوزيعات التكرارية وقيم الوسط الحسابي والانحراف المعياري تجاه العبارات (Z1 - Z5) الخاصة باستراتيجية منع التلوث، والتي تؤكد اتفاق الافراد المبحوثين على هذه العبارات، اذ بلغ نسبة الاتفاق (63.22\%)، وجاء ذلك بوسط حسابي (3.57) وانحراف

معياري (0.772)، وجاء هذا الاتفاق بمستويات استجابة متوسطة ما يعطي دلالة اولية على ان آراء افراد العينة تجاه منع التلوث تشير الى تبني الشركات قيد الدراسة استراتيجية الاستدامة البيئية التي تركز على تحسين الكفاءة البيئية للمنتجات للحد من النفايات والانبعاثات الناتجة عن العمليات الانتاجية. ومن خلال متابعة مدى اسهام كل فقرة تبين ان الشركات قيد الدراسة تعمل على نشر الثقافة والوعي الذاتي بين العاملين بالخخاطر التي يتسبب بها النلوث (Z4) هو الككر اسهاما اذ حظي ذلك باتفاق (74.2\%) من المبحوثين وبوسط حسابي مقداره (3.77) وانخراف معياري (0.845). ب. الرقابة على الانتاج: تبين من النتاجُ الواردة في الملحق (2) ان اجابات المبحوثين حول استراتيجية الرقابة على الانتاج من خلال مؤشراته (Z6 - Z10) والتي تؤكد على عدم اتفاق الافراد المبحوثين على هذه العبارات، اذ بلغت نسبة التوافر (43.88\%) من تلك الاجابات، مقابل عدم اتفاق (12.92\%) والنسبة المتبقية منهم (43.22\%) محايدون، وبوسط حسابي (3.35) وانخراف معياري (0.861). وهذا ما يدل على عدم توافر مؤشرات استراتيجية الرقابة على الانتاج في الشركات قيد الدراسة بحسب اراء الافراد المبحوثين. ج. التكنولوجيا النظيفة: تشير النتأُ الواردة في الملحق (2) ان اجابات المبحوثين حول استراتيجية النكنولوجيا النظيفة من خلال مؤشراته (Z11 - Z15) تؤكد على عدم اتفاق الافراد المبحوثين على هذه العبارات، اذ بلغت نسبة التوافر (43.88\%) من تلك الاجابات، مقابل عدم اتفاق (12.92\%) والنسبة المتبقية منهم (43.22\%) محايدون، وبوسط حسابي (3.35) وانحراف معياري (0.861). وهذا ما يدل على عدم توافر مؤشرات استراتيجية التكنولوجيا النظيفة في الشركات قيد الدراسة بحسب اراء الافراد المبحوثين. د. رؤية الاستدامة: تبين النتائج الواردة في الملحق (2) ان اجابات المبحوثين حول رؤية الاستدامة من خلال مؤشراته (Z16 - Z19) تؤكد على عدم اتفاق الافراد المبحوثين على هذه العبارات، اذ بلغت نسبة التوافر (49.2\%) من 


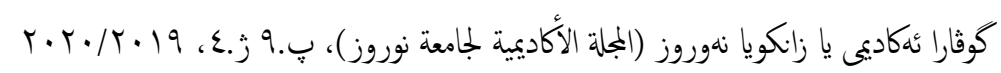

قيمة معامل الانحدار (Beta) (0.357) ما يعني أن استراتيجيات الاستدامة البيئية في عينة الدراسة ستتغير بمقدار (0.357) إذا أزداد الاهتمام بالتخطيط الإستراتيجي بعقدار وحدة واحدة وبدلالة قيمة (t) المحسوبة البالغة (2.059) والتي كانت اكبر من

$$
\text { قيمها الجدولية ايضاً. }
$$

\subsection{2 تاثير التخطيط الاستراتيجي في كل استراتيجية من استراتيجيات الاستدامة}

\section{البيئية على المستوى الكلي للثركات المبحوثة.}

يتضح من الجدول (6) انه لا يوجد هناك تأثير معنوي للتخطيط الاستراتيجي في استراتيجيات الاستدامة البيئة باستثناء استراتيجية التكنولوجيا النظيفة، حيث

كانت تأثير التخطيط الاستراتيجي في استراتيجية التكنولوجيا النظيفة معنوية بدلالة معامل التحديد (R2) إذ فسر هذا المؤشر لوحده (19.7\%) من التأثير الكلي، يدعمه

قيمة (F) المحسوبة (7.115). وبلغت قيمة (B1) (0.444) وهي قيمة معنوية بدلالة (t) (51) المحسوبة والبالغة (2.667).

\section{الجدول 6}

علاقة الأثر بين التخطيط الاستراتيجي في استراتيجيات الاستدامة البيئة على المستوى الكلي

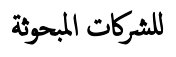

\begin{tabular}{|c|c|c|c|c|c|c|c|}
\hline \multirow[b]{2}{*}{ النتيجة } & \multirow[b]{2}{*}{ sig } & \multicolumn{5}{|c|}{ التخطيط الاستراتيجي } & \multirow{2}{*}{ المتغير المستقل } \\
\hline & & $\mathrm{R}^{2}$ & $\mathrm{~F}$ & $t$ & Beta & B & \\
\hline مرفوضة & 0.357 & $\% 0.29$ & 0.874 & 0.935 & 0.171 & 0.390 & منع التلوث \\
\hline مرفوضة & 0.255 & $\% 0.44$ & 1.349 & 1.162 & 0.211 & 0.269 & الرقابة على الانتاج \\
\hline مقبولة & 0.012 & $\% 19.7$ & 7.115 & 2.667 & 0.444 & 0.629 & التكنولوجيا النظيفة \\
\hline مرفوضة & 0.810 & $\% 0.02$ & 0.059 & 0.242 & 0.302 & 0.445 & رؤية الاستدامة \\
\hline مقبولة & 0.049 & $\% 12.7$ & 4.238 & 2.059 & 0.357 & 0.342 & المؤشر الكلي \\
\hline
\end{tabular}

المصدر: إعداد الباحثين في ضوء نتائج الحاسبة الكلكترونية

وعليه يتم قبول الفرضية الرئيسة الثانية والتي نصت على وجود أثر معنوي للتخطيط الاستراتيجي في استراتيجيات الاستدامة البيئية على المستوى الكلي لعينة الدراسة، اما فيا يخص الفرضيات المنثقة عنها فيتم قبول فقط الفرضية الفرعية الثالثة والتي تنص على وجود اثر معنوي للتخطيط الاستراتيجي في استراتيجية النكنولوجيا النظيفة وعلى مستوى على المستوى الكلي لعينة الدراسة، وتم رفض الفرضيات الفرعية الاولى والثانية والرابعة وقبول الفرضيات البديلة.

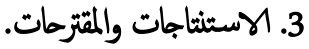

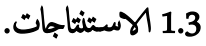

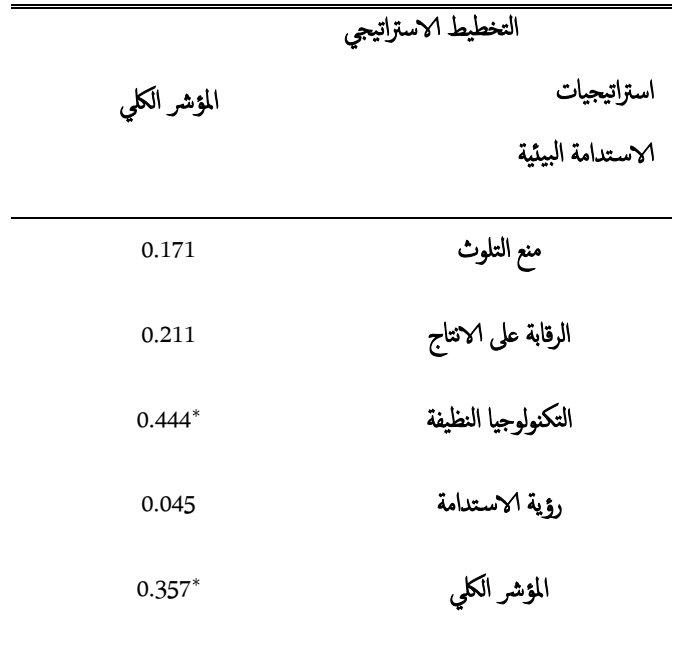

المصدر من إعداد الباحثين في ضوء نتائج الحاسبة الكلكتونية استناداً إلى ما سبق يتم قبول الفرضية الرئيسة الاولى التي نصت على فئ وجود علاقة ارتباط معنوية بين التخطيط الاستراتيجي واستراتيجيات الاستدامة البيئية على المستوى الكلي لعينة الدراسة. اما فيا يخص الفرضيات الفرعية، فيتم قبول فقط الفرضية الثالثة وعلى مستوى العينة قيد الدراسة ورفض الفرضيات الفرعية الاولى والثانية والرابعة وقبول الفرضيات البديلة. 3.2 تحليل علاقات الثاثير بين متغيرات الدراسة. لغرض معرفة مدى وجود تأثير معنوي لتخطيط الاستراتيجي في استراتيجيات الاستدامة البيئية فان انموذج الدراسة والفرضية الرئيسة الثانية تستلزم تحديد تأثير التخطيط الاستراتيجي في استراتيجيات الاستدامة البيئية بصورة كلية وجزئية، وهذا ما نصت عليه الفرضية الرئيسية الثانية والفرضيات الفرعية المنبثقة عنها، وفيا ياتيت تحليل اثر متغيرات الدراسة فضلاً عن تفسير المدلولات الهحصائية. 1.3.2 تأثير التخطيط الاستراتيجي في استراتيجيات الاستدامة البيئة على المستوى

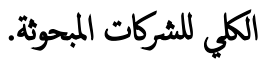
تشير نتائُ التحليل في الجدول (6) إلى وجود اثر معنوي للتخطيط الاستراتيجي في استراتيجيات الاستدامة البيئية ويدر ذلك قيمة (F) المحسوبة حيث بلغت (4.238) والتي هي اكبر من قيمها الجدولية (4.05) وعند مستوى معنوية (0.05) وبدرجات حرية $(29,1)$ مما يدل على ان منحنى الانحدار جيد في تفسير العلاقة بين التخطيط الاستراتيجي واستراتيجيات الاستدامة البيئية وعلى المستوى الكلي، وقد بلغ معامل التحديد ( R²) قيمة (0.127) والذي يشير إلى قدرة المتغير المستقل على تفسير الثاثير الذي يطرأ في استراتيجيات الاستدامة البيئية بنحو (12.7\%) ويعزز ذلك 


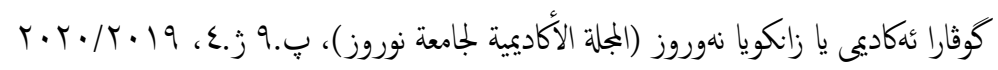

وذلك من خلال تشكيل لجان خاصة بتنفيذ التخطيط الاستراتيجيه وتقويمه تختلف عن لجان اعداد وصياغة التخطيط الاسترانيجي.

2. نظراً لافتقار الثركات عينة الدراسة إلى استراتيجيات الاستدامة البيئية وبشكل خاص التكنولوجيا النظيفة، يوصي الباحثان بضرورة استحضار التقنية النظيفة لانه تؤمن لهذه الشركات الوصول المى أفضل السلع وتلافيا لأي اثار سلبية لعمليات انتاجما ومنع التلوث سعيا لتحقيق الاستدامة. 3. توصي الدراسة الشركات المبحوثة على صياغة الاسترانيجيات التي تحقق المواءمة بين مواردها وقدراتها الداخلية من جهة ومتطلبات بينّها الخارجية من بجة أخرى بما يعزز من تحقيق اهدافها الاستراتيجية، ويتم ذلك عن طريق قيام الفاكنيات المبحوثة بتحديد توبهها الاستزاتيجي بالشكل الذي يأخذ توزيع مواردها وتعزيز

$$
\text { نقاط قوتها بنظر الاعتبار. }
$$

4. تقتزح الدرسة أن تستخدم الشركات المبحوثة المرشحات والمرسبات الكهربائية والوسائل الميكانيكية الأخرى كالأبراج ومعدات الاحتراق الخاصة وغيرها حيث

تتناسب مع طبيعة الملوثات المنطلقة والمطلوب التحكم فيها.. 5. على الشركات المبحوثة ان تمتلك رؤية واضحة عن التوجه نحو الاستدامة البيئية في المستقبل، ويكن الاستفادة من هذه الناحية من منظلات حاية البيئة لما له

$$
\text { من إثر على السمعة البيئية للشركة. }
$$

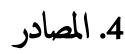

\section{4}

1. ابو دولة، جال داود، وصالحية، لؤي محم، (2005)، تثيم مستوى مارسة التخطيط الاستراتيجي في إدارة الموارد البشرية، دراسة مقارنة بين منظات القطايين العام والخاص الاردنية، المجلة العربية للادارة، مج (25)، العدد (1)، المنظمة العربية للتنمية، القاهرة، مصر. 2البرادعي، بسيوني محد، (2005)، تنمية هارات تخطيط الموارد البشرية، ربط تخطيط الموارد

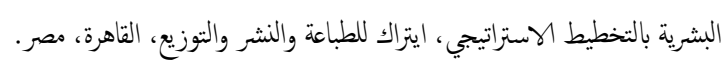

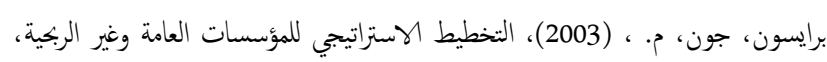
ترجمة: محمد عزت عبد الموجود، مكتبة لبنان ناشرون، بيروت، لبنان.

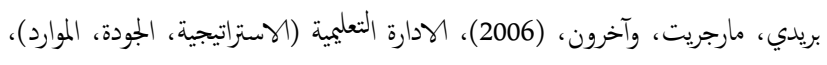

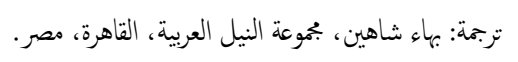
توفيق، عبدالرمن (2004)، منهج الإدارة العليا: التخطيط الاستراتيجي والتفكير الإبداعي، ط3، مركز الخبرات المهنية للإدارة "هيكيك، القاهرة، مصر. متوفر على الموقع الالكتروني:
يتناول هذا المحور أهم الاستنتاجات التي توصلت الهيا الدراسة وهي: 1. دلت ننائُ التحليل الوصفي على ان اجابات المبحوثين كانت مثفقة على توافر

$$
\text { مؤشرات التخطيط الاستراتيجي في الشركات المبحوثة. }
$$

2. اشارت نتاجُج التحليل الوصفي إلى ان اجابات المبحوثين كانت غير متفقة على له

$$
\text { توافر استراتيجيات الاستدامة البيئية في الشركات المبحوثة. }
$$

3. تبين من نتاجُ التهليل الوصفي ان التوجه الاستراتيجي كانت من اكثر مؤشرات

التخطيط الاستراتيجي وجودا في الشركات قيد الدراسة، وان استراتيجية

التكنولوجيا النظيفة كانت من اقل الاستراتجيات وجوداً في الشركات المبحوثة.

4. دلت نتائُ التحليل على وجود علاقة ارتباط معنوية بين التخطيط الاستراتيجي

واستراتيجيات الاستدامة البيئية (المؤشر الكلي) في الشركات المبحوثة، في حين كانت العلاقة غير معنوية بين التخطيط الاستراتيجي واستراتيجيات الاستدامة

البيئية باستثناء العلاقة بين التخطيط الاستراتيجي واستراتيجية التكنولوجيا النظيفة حيث كانت العلاقة معنوية.

5. اظهرت نتائُ تحليل الانحدار وجود علاقة تأثير معنوية للتخطيط الاستراتيجي في استراتيجيات الاستدامة البيئية (المؤشر الكلي) في الشركات المبحوثة، في حين لم يككن هناك تاثير معنوي التخطيط الاستراتيجي في كل استراتيجية من استراتيجيات الاستدامة البيئية باستثناء استراتيجية التكنولوجيا النظيفة حيث كان الثأثير معنوي.

6. تبين من نتأجُ التحليل الوصفي توفر مؤشرات التخطيط الاستراتيجي في الشركات المبحوثة بنسبة ضعيفة، في حين دلت نتائج الانحدار إلى أن استراتيجيات الاستدامة البيئية تستمد من مؤشرات التخطيط الاستراتيجي، وهذا ما يفسر قيام القيادة الإدارية في هذه الشركات باستغلال مؤشرات التخطيط الاستراتيجي بكفاءة.

2.3

سيتم تخصيص هذا المحور لندوين توصيات الدراسة وهي: 1. نظراً لافتقار الشركات عينة الدراسة إلى مؤشرات التخطيط الاستراتيجي وبشكل خاص مؤشر التقويم، يوصي الباحثان بضرورة الاهتمام بهذا المؤشر لماله من تأثير في عملية التخطيط الاستراتيجي والاستفادة من التغذية العكسية، 


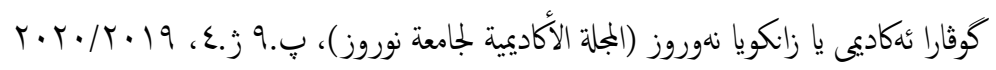

1. BASIAGO, A. D. , (1999), Economic, social, and environmental sustainability in development theory and urban planning practice,

The Environmentalist ,19, 145-161.

2. Gamage, T.C. and Abeysinghe, D. (2010). Strategy for Achieving Ecological Sustainability while Improving Business Performance: A Field Study in Textile \& Clothing Industry, In: Proceedings of the 1st International Conference on Business and Information, University of Kelaniya.

3. Kotler,Philip\&Armstrong,Gary,2011,"Marketing",10 $10^{\text {th }}$ Ed,prentice Hall

4. Menzies, G.F. and Wherrett, J.R., (2005), Windows in the workplace: examining issues of environmental sustainability and occupant comfort in the selection of multi-glazed windows, Energy and Buildings, 37 (2005) 623-630.

5. Morelli, John (2011) "Environmental Sustainability: A Definition for Environmental Professionals," Journal of Environmental Sustainability: Vol. 1: Iss. 1, Article 2.

6. Munitz, Barry. Chancellor, CSU. (February 1, 1995). Presentation at CSUN: Trends in Higher Education. Northridge, CA. Available at: $\underline{\text { www.csun.edu. }}$

7. Pogutz, Stefano; Micale, Valerio; and Winn, Monika (2011) "Corporate Environmental Sustainability Beyond Organizational Boundaries: Market Growth, Ecosystems Complexity and Supply Chain Structure as Co-Determinants of Environmental Impact, Journal of Environmental Sustainability: Vol. 1: Iss. 1, Article 4.

8. Siche , J.R. , Agostinho, F., Ortega, E. and Romeiro, A., (2007), Sustainability of nations by indices: Comparative study between environmental sustainability index, ecological footprint and the emergy performance indices, Ecological Economics.

9. Sutton, Philip, (2004), A Perspective on environmental sustainability? A paper for the Victorian Commissioner for Environmental Sustainability, http://www.green-innovations.asn.au. 1http://www.arabslink.net/vb/register.php

AM : 2008/2/5

6. الزهراني، سعد عبدالله بردي، (2004)، التخطيط الاستراتيجي لمؤسسات التعليم العالي،

مركز البحوث التزبوية والنفسية بجامعة أم القرى، مكة المكرمة، السعودية. متوفر على الموقع

الكلكتروني: http://www.arabslink.net/vb/register.php، تاريخ الاطلاع على

نيت: 2008/2/5 :

7. السبتي، علي احمد، (2005)، التخطيط الهستراتيجي، جريدة الرياض الككترونية، الجمعة /

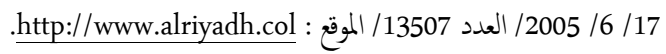

8. السلطان، خالد صاح، (2006)، التفكير والتخطيط الاستراتيجي في مؤسسات التعليم

العالي مشروع آفاق نموذجاً، الملتقى الإداري الرابع للجمعية السعودية للإدارة، الرياض،

المملكة العربية السعودية.

العارف، نادية، (2005)، الادارة الاستراتيجية، ط3، الدار الجامعية، الاسكندرية، جمهورية المصر العربية.

10. عبد الجليل، هويدي، (2014)، العلاقة التفاعلية بين السياحة البيئية والتنمية المستدامة،

مجلة الدراسات والبحوث الاجتمية - جامعة الوادي، العدد 90 ، ص ص 211- 225.

11. القطامين، احم، (2002)، الادارة الاستراتيجية مفاهيم وحالات تطبيقية، دار مجدلاوي

اللنشر والتوزيع، عمان، الاردن.

12. الكبيسي، عامر خضير حميد، (2006)، التخطيط الاستراتيجي للقيادات التربوية، جامعة

نايف العربية للعلوم الامنية، الرياض، السعودية، بحث متوفر على الموقع الكلكتوني للجامعة: PM :2018/3/16: تاريخ الاطلاع على نيت: http://www.nauss.edu.sa 13. المبارك، معصومة صالح، (2006)، القيادة والتفكير الاستراتيجي الطريق إلى المستقبل، الملتقى الإداري الرابع للجمعية السعودية للإدارة، الرياض، المملكة العربية السعودية. 14. محد، انس ساتي ساتي، (2014)، قراءات حول فلسفة التنمية المستدامة، مجلة الدراسات المالية والمصرفية، المجلد (22)، العدد (4). 15. منصوري، كمال محمد ورمزي، جودي محم، (2008)، المراجعة البيئية كأحد متطلبات المؤسسة المستدامة وتحقيق التنمية المستدامة، المؤثمر الدولي العلمي: النتمية المستدامة والكفاءة الاستخدامية للموارد المتاحة، كلية العلوم الاقتصادية وعلوم التسيير، جامعة فرحات عباس - سطيف، 7-7/ 4/ 208، الجمهورية الجزائرية الديمقراطية الشعبية. 16. الهلالي، حسين مصطفى، (2006)، التخطيط الاستراتيجي وتصميم السلوك الاستراتيجي للمنظمة، ندوة التخطيط الاستراتيجي لنظم وشبكات المعلومات، القاهرة، جمهورية مصر العربية.

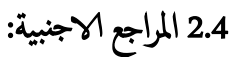




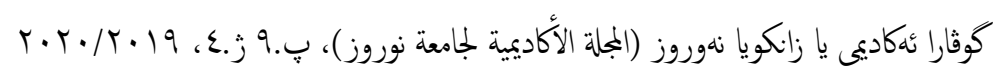

10. Thambusamy, Ravi, and Salam, A. F., (2010), Corporate Ecological responsiveness, Environmental Ambidexterity And It-Enabled Environmental Sustainability Strategy, Thirty First International Conference on Information Systems, St. Louis 2010.

11. Wright ,Richard T.\& Boorse ,Dorothy F., (2011), Environmental Science, $7^{\text {th }}$ Ed, pearson Benjamin eummings. 


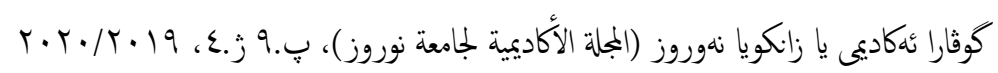

الملحق (1)

جامعة دهوك كلية الإدارة والاقتصاد دموك

استمارة استبيان

$$
\text { تحضة طية.... }
$$

نضع بين أيديكم استبياناً خاصاً بجمع البيانات المتعلقة بإنجاز البحث الموسوم (دور التخطيط الاستراتيجي في تعزيز استراتيجيات الاستدامة البيئية: دراسة استطلاعية

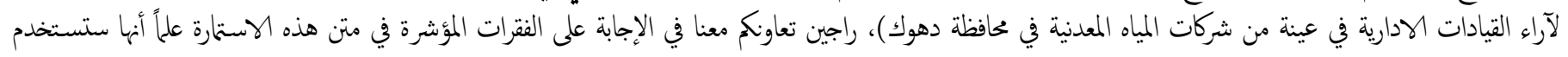

$$
\begin{aligned}
& \text { لأغراض البحث العلمي. } \\
& \text { ملاحظات: } \\
& \text { 1- يرجى وضع علامة ( ل ل ) في الحقل الذي تراه مناسباً من وبجة نظرك. } \\
& \text { 2- يرجى الإجابة على جميع الأسئلة علماً أن تزك أي سؤال دون الإجابة يعني عدم صلاحية الاستمارة للتحليل والقياس. } \\
& \text { 3- سيتم التعامل مع إجاباتكم بسرية وستعرض النتائج الإجالية بشكل أعداد و مجاميع ومؤشرات إحصائية عامة و ستستعمل لأغراض هذا البحث العلمي حصراً. } \\
& \text { ولىم منا جزيل الشكر والتقدير. }
\end{aligned}
$$

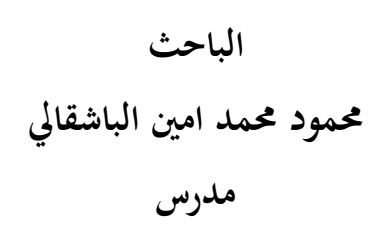

الباحث

د. حكمت رشيد سلطان

استاذ مساعد 


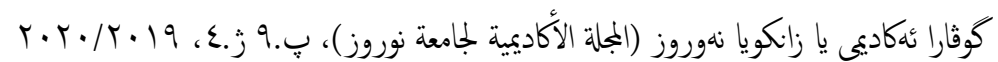

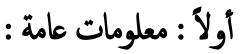

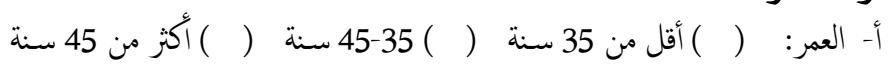

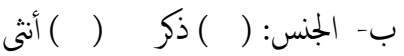

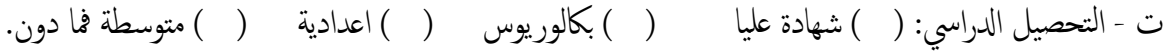

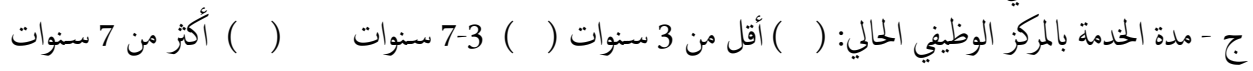

ثانياً/ البيانات الأساسية: المحور الأول: التخطيط الهات الاستراتيجي. 1- التوجه الاستراتيجي للمصنع.

\begin{tabular}{|c|c|c|c|c|c|c|}
\hline لا لا بفق & لا لاتق & متأكد & اتقق & بثدة - اتفق & 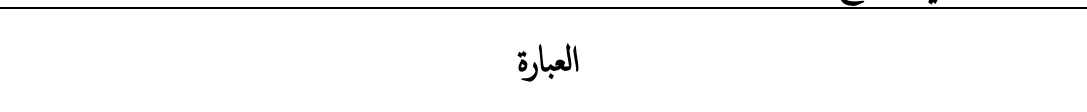 & ت \\
\hline & & & & & يجدد المصنع غرضه وطريقة بلوغه للأمد الطويل. & 1 \\
\hline & & & & & يعمل المصنع على تحديد الاهداف الممكن تحقيقها وتطويرها مع ما يجري من مستجدات عالمية. & 2 \\
\hline & & & & & يمتلك المصنع رؤية واضحة عن تحقيق ابعاد الجودة في الانتاج. & 3 \\
\hline & & & & & للعتبر صياغة وتحديد المستقبل المرغوب فيه وأساليب تحقيقه عنصر جوهري في التخطيط الاسترانيجي & 4 \\
\hline & & & & & يقوم المصنع بتزويد المجتع بالمنتوجات وفقاً للمعايير الاخلاقية والاجتماعية والثقافية للمجتمع. & 5 \\
\hline & & & & & الظروف المحلية. & 6 \\
\hline & & & & & يعمل المصنع على دمج مفهوم الجودة في نسيج المنظومة الانتاجية والخدمية. & 7 \\
\hline & & & & & يعمل المصنع على تحقيق الأهداف التي تنسجم مع رساتها. & 8 \\
\hline & & & & & يضع المصنع الإمكانات المادية والبشرية الكافية لتحقيق الأهداف الإستراتيجية. & 9 \\
\hline
\end{tabular}

2- التحليل البيتي: (نقاة القوة والضعف الداخلية، الفرص والهديدات الخارجية):

\begin{tabular}{|l|l|r|r|r|r|c|}
\hline & & & & \\
\hline \\
\hline
\end{tabular}




\begin{tabular}{|c|c|c|c|c|c|c|}
\hline لا لأثق & لا آتقق & متأكد & أثقق & 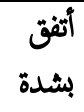 & 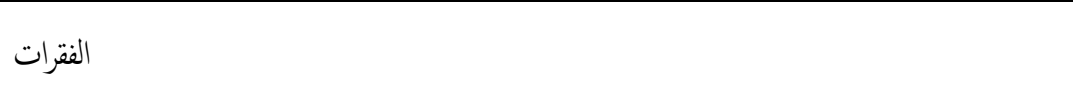 & $ت$ \\
\hline & & & & & يسعى المصنع لصياغة الاستراتيجيات التي تحقق الموائمة بين مواردها وقدراتها الداخلية من بهة ومتطلبات البئة الخارجية من بحة أخرى. & 17 \\
\hline & & & & & يسعى المصنع لتوفير الامكانات والموارد المتاحة ومتطلبات تطبيق الاستراتيجية. & 18 \\
\hline & & & & & يمتلك المصنع هيكل تنظيمي ملائم لتطبيق الإستراتيجية. & 19 \\
\hline & & & & & ميئئ المصنع الافراد في جميع المستويات والقادرين على تنفيذ التخطيط الاستراتيجي. & 20 \\
\hline
\end{tabular}

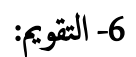

\begin{tabular}{|c|c|c|c|c|c|c|}
\hline لا آثقدة & لا لا تقفق & غتاكد & أتفق & بشدة & 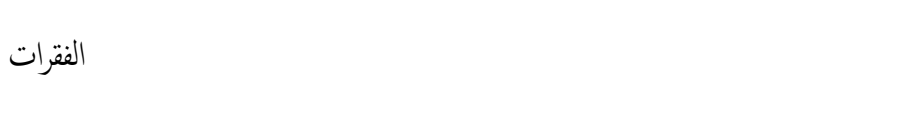 & ت \\
\hline & & & & & يعمل المصنع على تقييم اداء فريق العمل المكلف بتخطيط وتنفيذ الأهداف الإستراتيجية. & 21 \\
\hline & & & & & يتبع المصنع منهجاً للتحسين المستمر في اعالها وصولاً إلى تحقيق أهدافها الإستراتيجية. & 22 \\
\hline & & & & & يقوم المصنع باتباع اسلوب تجنب الاخطاء بدلاً من تصحيحها. & 23 \\
\hline & & & & & يستطيع المصنع تشخيص مشاكل تطوير العملية الانتاجية واسباها. & 24 \\
\hline
\end{tabular}

المور الثاني: استراتيجيات الاستدامة البيئية. وتشل:

\begin{tabular}{|l|l|l|l|l|r|c|}
\hline - 1 1 & \\
\hline \\
\hline
\end{tabular}

\begin{tabular}{|c|c|c|c|c|c|c|}
\hline 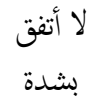 & أنق أنق & غنر متاكد & أتفق & 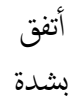 & 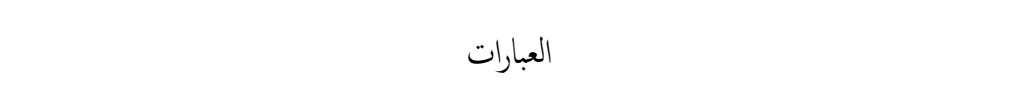 & $ت$ \\
\hline & & & & & تعتمد ادارة المصنع مواد غير ملوثة عبر دراسة خصائص مكونات المواد الاولية التي تستخدها. & 6 \\
\hline & & & & & تخصص ادارة المصنع باستمرار جزءا من ايراداتها لانشطة البحث والتطوير لغرض استبدال المواد & 7 \\
\hline & & & & & يوظف المصنع استراتيجية تقلل من المخلفات في كافة مراحل عملياتها الانتاجية. & 8 \\
\hline & & & & & يعمل المصنع على ايقاف اية عملية انتاجية التي تنبعث منها نسبة غازات عالية. & 9 \\
\hline & & & & & يتم التخلص من المنتجات الهالكة حسب القوانين والتعليمات الخاصة بحاية البيئية من التلوث. & 10 \\
\hline
\end{tabular}




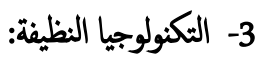

\begin{tabular}{|c|c|c|c|c|c|c|}
\hline لا لا أتفق & لا آتفق & غنر متاكد & أتفق & بشدة & 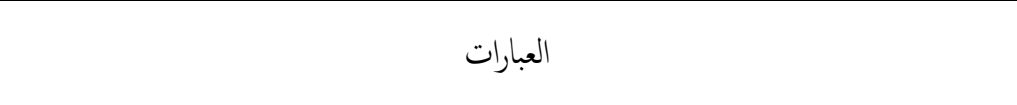 & ت \\
\hline & & & & & يعد نظام الانتاج المعتمد في المصنع اساسا في تحديد كمية ملوثات وخخلفات عملياتها. & 11 \\
\hline & & & & & ينتاجما. & 12 \\
\hline & & & & & يعمد المصنع تغيير التقنيات عند ارتفاع معدلات استهلاك الطاقة التي تستخدم فيها. & 13 \\
\hline & & & & & يقوم المصنع بتطوير وسائل الإنتاج باستمرار من خلال إدخال تقنيات حديثة اقل إحداثا للنلوث. & 14 \\
\hline & & & & & 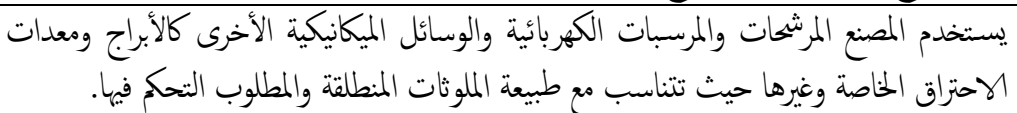 & 15 \\
\hline
\end{tabular}

4- رؤية الاستدامة:

\begin{tabular}{|c|c|c|c|c|c|c|}
\hline لا لا بنق & لا لا أتفق & غتاكد & أتفق & بشدة & 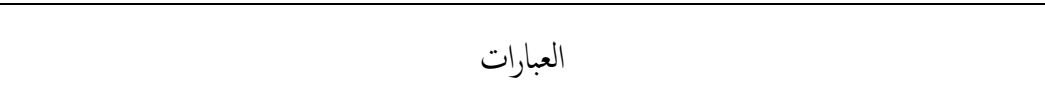 & ت \\
\hline & & & & & يمتلك المصنع رؤية واضحة عن التوجه نخو الاستدامة البيئية في المستقبل. & 16 \\
\hline & & & & & يعتبر توفير الطاقة والحد من استنزاف الموارد الطبيعية والحفاظ عليها لتحقيق الاستدامة من & 17 \\
\hline & & & & & يمتلك المصنع القدرة على النعامل مع القضايا البيئية التي توابحه. & 18 \\
\hline & & & & & يؤمن المصنع بانه لا يمكن تحتيق التنية على قاعدة تتدهور فيها الموارد الطبيعية. & 19 \\
\hline
\end{tabular}

الملحق (2)

التوزيعات التكرارية وقيم الوسط الحسايي والانحراف المعياري على مستوى الثركات قيد الثراسة (n=31)

\begin{tabular}{|c|c|c|c|c|c|c|c|c|c|c|c|c|c|c|}
\hline \multirow{2}{*}{ S.D } & \multirow{2}{*}{ Mean } & \multicolumn{2}{|c|}{ لا اتفق بشدة } & \multicolumn{2}{|c|}{ لا اتفق } & \multicolumn{2}{|c|}{ محايد } & \multicolumn{2}{|c|}{ اتفق } & \multicolumn{2}{|c|}{ اتفق بشدة } & & \multirow{2}{*}{ |لموتشرات| المتجيات } & \multirow{2}{*}{$\frac{\overline{3}}{3}$} \\
\hline & & $\%$ & العدد & $\%$ & العدد & $\%$ & العدد & $\%$ & العدد & $\%$ & العدد & & & \\
\hline 0.677 & 3.48 & 0 & 0 & 6.5 & 2 & 41.9 & 13 & 48.4 & 15 & 3.2 & 1 & $\mathrm{X} 1$ & \multirow{11}{*}{ الاستراتيجي } & \multirow{17}{*}{ الاستراتيحيط } \\
\hline 0.615 & 3.61 & 0 & 0 & 3.2 & 1 & 35.5 & 11 & 58.1 & 18 & 3.2 & 1 & $\mathrm{X} 2$ & & \\
\hline 0.709 & 3.65 & 0 & 0 & 3.2 & 1 & 38.7 & 12 & 48.4 & 15 & 9.7 & 3 & $\mathrm{X} 3$ & & \\
\hline 0.514 & 3.74 & 0 & 0 & 0 & 0 & 29 & 9 & 67.7 & 21 & 3.2 & 1 & $\mathrm{X} 4$ & & \\
\hline 0.680 & 3.94 & 0 & 0 & 0 & 0 & 25.8 & 8 & 54.8 & 17 & 19.4 & 6 & $\mathrm{X} 5$ & & \\
\hline 0.746 & 4.10 & 0 & 0 & 3.2 & 1 & 12.9 & 4 & 54.8 & 17 & 29 & 9 & $\mathrm{X} 6$ & & \\
\hline 0.875 & 3.97 & 0 & 0 & 3.2 & 1 & 29 & 9 & 35.5 & 11 & 32.3 & 10 & $\mathrm{X} 7$ & & \\
\hline 0.898 & 3.84 & 0 & 0 & 6.5 & 2 & 29 & 9 & 38.7 & 12 & 25.8 & 8 & $\mathrm{X} 8$ & & \\
\hline 0.886 & 3.58 & 0 & 0 & 12.9 & 4 & 29 & 9 & 45.2 & 14 & 12.9 & 4 & X9 & & \\
\hline \multirow[b]{2}{*}{0.733} & \multirow[b]{2}{*}{3.77} & \multicolumn{2}{|c|}{0} & \multirow{2}{*}{\multicolumn{2}{|c|}{4.30}} & \multirow{2}{*}{\multicolumn{2}{|c|}{30.09}} & & 50.18 & & 15.41 & \multirow{2}{*}{ المعدل } & & \\
\hline & & \multicolumn{2}{|c|}{4.30} & & & & & \multicolumn{4}{|c|}{65.59} & & & \\
\hline 0.962 & 3.48 & 3.2 & 1 & 9.7 & 3 & 35.5 & 11 & 38.7 & 12 & 12.9 & 4 & $\mathrm{X} 10$ & \multirow{6}{*}{ التحليل البيئي } & \\
\hline 0.848 & 3.58 & 0 & 0 & 6.5 & 2 & 45.2 & 14 & 32.3 & 10 & 6.1 & 5 & X11 & & \\
\hline 0.765 & 3.58 & 0 & 0 & 6.5 & 2 & 38.7 & 12 & 45.2 & 14 & 9.7 & 3 & $\mathrm{X} 12$ & & \\
\hline 0.851 & 3.52 & 0 & 0 & 9.7 & 3 & 41.9 & 13 & 35.5 & 11 & 12.9 & 4 & $\mathrm{X} 13$ & & \\
\hline 0.919 & 3.61 & 0 & 0 & 9.7 & 3 & 38.7 & 12 & 32.3 & 10 & 19.4 & 6 & X14 & & \\
\hline 0.992 & 3.58 & 0 & 0 & 19.4 & 6 & 19.4 & 6 & 45.2 & 14 & 16.1 & 5 & $\mathrm{X} 15$ & & \\
\hline
\end{tabular}




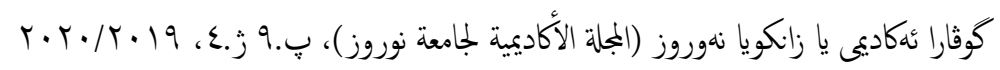

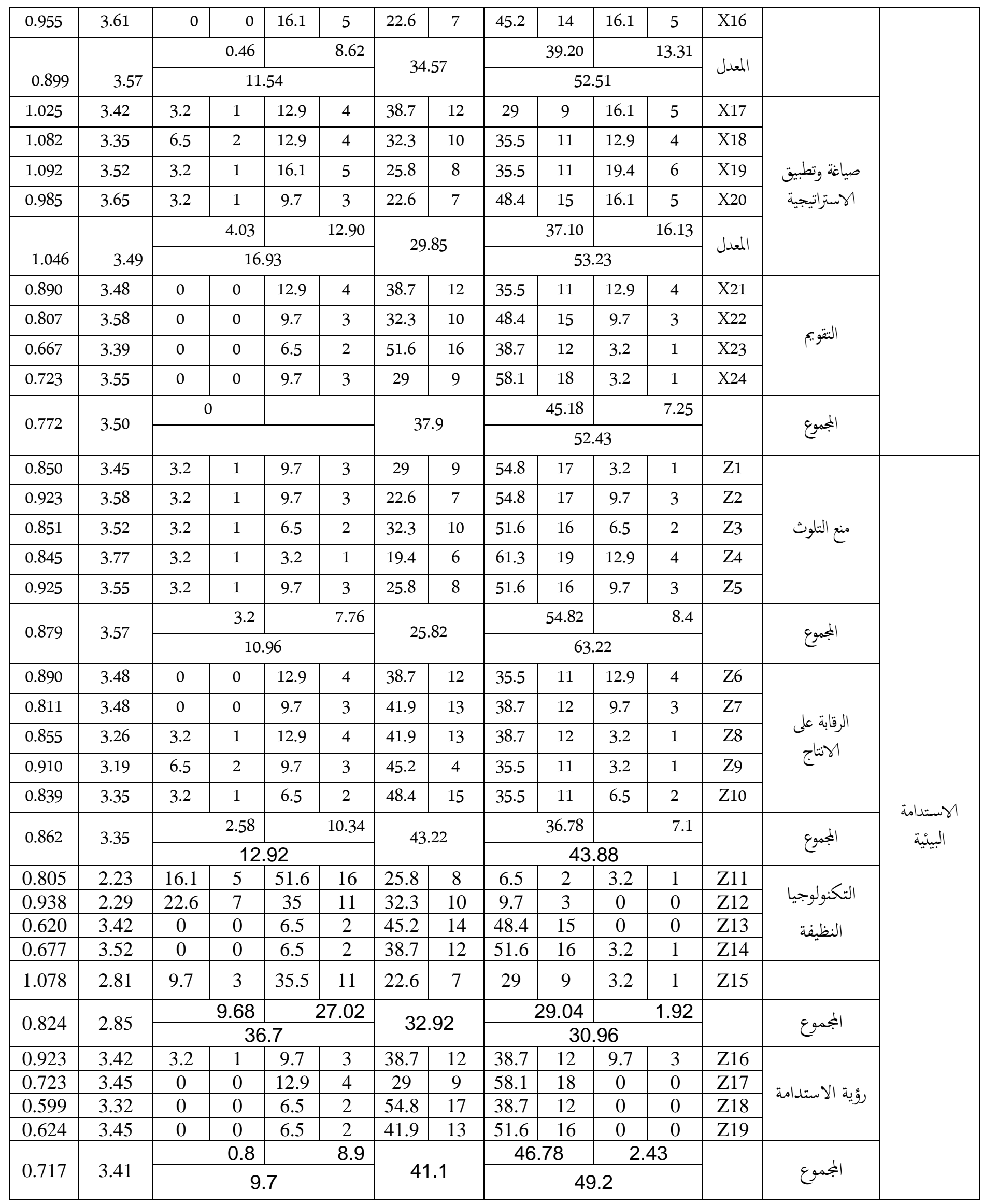

